Article

\title{
Hybrid Pumped Hydro Storage Energy Solutions towards Wind and PV Integration: Improvement on Flexibility, Reliability and Energy Costs
}

\author{
Mariana Simão*(-) and Helena M. Ramos (1) \\ Civil Engineering, Architecture and Georesources Department, CERIS, Instituto Superior Técnico, \\ Universidade de Lisboa, 1049-001 Lisboa, Portugal; hramos.ist@gmail.com or helena.ramos@tecnico.ulisboa.pt \\ * Correspondence: m.c.madeira.simao@tecnico.ulisboa.pt
}

Received: 16 June 2020; Accepted: 29 August 2020; Published: 1 September 2020

\begin{abstract}
This study presents a technique based on a multi-criteria evaluation, for a sustainable technical solution based on renewable sources integration. It explores the combined production of hydro, solar and wind, for the best challenge of energy storage flexibility, reliability and sustainability. Mathematical simulations of hybrid solutions are developed together with different operating principles and restrictions. An electrical generating system composed primarily by wind and solar technologies, with pumped-storage hydropower schemes, is defined, predicting how much renewable power and storage capacity should be installed to satisfy renewables-only generation solutions. The three sources were combined considering different pump/turbine $(\mathrm{P} / \mathrm{T})$ capacities of 2, 4 and $6 \mathrm{MW}$, wind and PV solar powers of 4-5 MW and 0.54-1.60 MW, respectively and different reservoir volume capacities. The chosen hybrid hydro-wind and PV solar power solution, with installed capacities of 4, 5 and $0.54 \mathrm{MW}$, respectively, of integrated pumped storage and a reservoir volume of $378,000 \mathrm{~m}^{3}$, ensures $72 \%$ annual consumption satisfaction offering the best technical alternative at the lowest cost, with less return on the investment. The results demonstrate that technically the pumped hydro storage with wind and PV is an ideal solution to achieve energy autonomy and to increase its flexibility and reliability.
\end{abstract}

Keywords: pumped hydro storage (PHS); hybrid hydro-wind-solar solutions; technical feasibility; new power generation

\section{Introduction}

Hydropower plays an important role today and will become even more important in the coming decades, since hydropower can be a catalyst for the energy transition in Europe [1]. The ambitious plan for energy transition in Europe seeks to achieve a low-carbon climate-resilient future in a safe and cost-effective way, serving as a worldwide example [2]. The key role of electricity will be strongly reinforced in this energy transition. In many European countries, the phase out of nuclear and coal generation has started with a transition to new renewable sources comprising mainly of solar and wind for electricity generation. However, solar and wind are variable energy sources and difficult to align with demand. Hydropower already supports integration of wind and solar energy into the supply grid through flexibility in generation as well as its potential for storage capacity. These services will be in much greater demand in order to achieve the energy transition in Europe, and worldwide [1,2].

Hydropower, with its untapped potential, has all the characteristics to serve as an excellent catalyst for a successful energy transition. However, this will require a more flexible, efficient, environmentally and socially acceptable approach to increasing hydropower production to complement wind and solar energy production. In particular, (a) increasing hydropower production through the implementation of 
new environmentally friendly, multipurpose hydropower schemes and by using the hidden potential in existing infrastructure; (b) increasing the flexibility of generation from existing hydropower plants by adaptation and optimization of infrastructure and equipment combined with innovative solutions for the mitigation of environmental impacts and (c) increasing storage by the heightening of existing dams and the construction of new reservoirs, which have to ensure not only flexible energy supply but also support food and water [2]. Therefore, a hybrid system between several renewable energy resources, a complementary nature among other sources in an integrated and flexible way is of utmost importance in the electric producer system and energy management. The most traditional and mature storage technology, pumped hydro storage, is adopted to support both the grid connection, as well as the standalone hybrid hydro-wind-solar grid system.

Energy and water are closely interlinked. These interconnections intensify as the demand for resources increases with population growth and changing consumption patterns [3]. Due to the growing awareness about environment, climate changes, pollution and waste footprint, clean and renewable sources of energy are being encouraged and used globally. With these growing trends of using intermittent renewable sources of energy, there will be a greater need to make flexible the modern energy production and distribution systems. The challenge of using renewable sources such as hydro, wind and solar energies is their variability, intermittency, non-predictability and under-weather dependency [4]. Kapsali and Kaldellis [5] assessed the techno-economic viability of a system incorporating simultaneous wind farms with pumped storage and hydro turbines for remote islands and determined that the contribution of renewable energy was increased by $15 \%$. Castronuovo et al. [6] worked on optimum operation and hydro storage sizing of a wind and hydro hybrid power plant and calculated an annual profit of $11.91 \%$ by purchasing energy during periods of low demand and selling during periods of high demand. Vieira et al. [7] studied optimization and operational planning of wind and hydro hybrid water supply systems and concluded that up to $47 \%$ of energy costs can be saved in the optimization mode compared to normal operating mode. More detailed information can be found in [8-11] on feasibility, optimal design and operation of pumped-hydro hybrid systems.

Combining renewable energy resources is the best way to overcome energy shortcomings, which not only provides more reliable power systems increasing the storage capacity but also leads to the reduction in climate change effects [1,12]. In addition, renewable-based technologies can make water accessible for domestic, industry and agricultural purposes, improving supply security while decoupling growth in water from fossil fuels. Renewable energy technologies offer opportunities to address trade-offs and to leverage on synergies between sectors to enhance water and energy nexus. However, connecting renewable power plants to the grid can cause dynamic controlling problems if the electricity network is not prepared for handling such variations due to the intermittency of renewable sources availability [13]. Therefore, a continuous and reliable power supply is hardly possible without energy storage. Using an energy storage system, the surplus energy can be stored when the power generation exceeds the demand and then released to cover the periods when the net load exists, providing a robust flexible back-up for intermittent renewable energy sources $[14,15]$. This has the advantage in increasing the system flexibility and reliability, decreasing the variability of renewable sources availability, since the variable power output can be levelled out due to a complementary nature between renewable resources through their integration in the hydropower by a pumped storage solution.

Although an oversized hybrid system satisfies the load demand, it can be an unnecessarily expensive solution. An undersized hybrid system is more cost-effective but may not be able to meet the load demand. The optimum size of the hybrid renewable energy power system depends on several simulations based on specific mathematical models and system components management towards the best solution [16]. This study discusses the implications of a water-energy nexus focusing on renewable energy technologies, a cost-effective and environmentally sustainable supply of energy. It examines a specific case to highlight how renewable energy can address the trade-offs, helping to 
state the world's pressing water and energy challenges towards an optimization model development and application.

This work presents a consistent framework for optimizing the availability and storage of renewable resources and to evaluate how the system behaves with changing the power capacity, in order to facilitate such complementarity in a flexible and multi-variable process. Different solutions are analyzed, according to the demand and the installed power, for different storage volumes, and different available characteristics for pump/hydro, wind and solar energy sources. The complementarity and the system flexibility to satisfy the consumption is a complex solution with several characteristic parameters that need to be solved simultaneously using different time series for the available sources.

\section{Hybrid and Pumped Storage Technologies}

\subsection{Characterization}

Pumped hydropower storage (PHS) accounts over 94\% of installed global energy storage capacity and retains several advantages such as lifetime cost, levels of sustainability and scale. The existing 161,000 megawatts (MW) of pumped storage capacity support power grid stability, as significant water batteries, reducing overall system costs and sector emissions [1]. PHS operations and technology are adapting to the changing power system requirements incurred by variable renewable energy (VRE) sources as a new energy transition solution. Variable-speed and ternary PHS systems allow for faster and wider operating ranges, providing additional flexibility, enabling higher penetrations of VRE at lower system costs at high reliable levels. As traditional revenue streams become more unpredictable and markets are volatiles, PHS is seen to secure long-term revenue in order to attract investment, particularly in liberalized energy markets [1,2].

Different energy resources can be combined building an integrated hybrid energy system that complements the drawbacks existing in each individual energy solution. Therefore, the design goals for hybrid power systems are the minimization of power production cost, purchasing energy from the grid (if it is connected), the reduction of emissions, the total life cycle cost and increasing the reliability and flexibility of the power generation system [17-19]. The pumped storage can be seen as the most promising technology to increase renewable energy levels in power systems. Hydro, wind, solar and pumped hydro storage (PHS), as hybrid power solutions, constitute a realistic and feasible option to achieve high renewable levels, considering that their components are properly sized. In some locations, the solar and wind resources have an anti-correlation, complementing each other and giving a combined less variable output than independently [20].

Pumped-storage schemes currently provide the most commercially important means of large-scale grid energy storage and improve the daily capacity factor of the generation system. Pumped hydropower energy storage stores energy in the form of potential energy that is pumped from a lower reservoir to a higher one putting the water source available to turbine to fit the energy demand. In this type of system, low cost electric power (electricity in off-peak time) is used to run the pumps to raise the water from the lower reservoir to the upper one [21]. During the periods of high power demand, the stored water is released through hydro turbines to produce power. Reversible turbine-generator groups act as pump or turbine, when necessary. A typical conceptual pumped hydro storage system with wind and solar power options for transferring water from lower to upper reservoir is represented in Figure 1.

This system is equipped with a photovoltaic (PV) system array, a wind turbine, an energy storage system (pumped-hydro storage), a control station and an end-user (load). This whole system can be isolated from the grid, i.e., a standalone system or in a grid connection where the control station can be the grid inertia capacity. This is currently the most cost-effective means of storing large amounts of renewable energy, based on decisive factors, such as, capital costs, suitable topography and climate changes challenges [22]. 


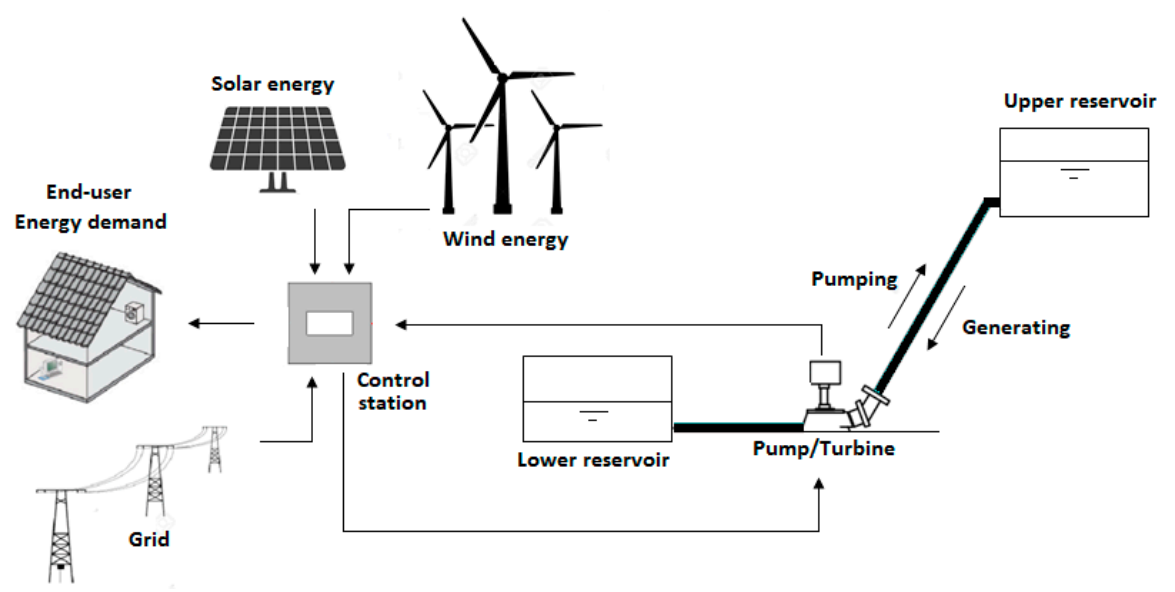

Figure 1. A hybrid hydro-wind-solar system with pumped storage system.

\subsection{Optimal Design of a Hybrid System}

\subsubsection{Dispatch Optimization Model}

The purposed mathematical model can predict how much wind, solar power and pumped hydro-storage energy capacity should be installed to satisfy a hybrid renewable solution. Wind is highly fluctuating meteorological parameter changing every hour and annually. Therefore, to connect wind power with the grid and assure quality power supply, large energy storage systems are required. Nevertheless, different types of wind turbines may output different power due to their difference in the power curve characteristics. Therefore, the model used to describe the performance should be different [23-26]. As for solar energy although less fluctuating, it only works during day light hours. It offers more reliable power and can be committed and managed, using relatively smaller energy storage systems to provide continuous and quality power [27]. According to [19], pumped hydropower storage plants have several advantages, such as (1) flexible start/stop and fast response speed, (2) ability to track load variations and adapt to severe load changes, (3) capacity to modulate the frequency and maintain voltage stability and face climate change and reduce footprint effects on an integrated solution.

The optimal design of a hybrid solar-wind-system supported by a pumped-based hydro scheme can significantly enhance the technical and economic performance for efficient energy harnessing. The multi-variable techniques are also known for their accuracy and simplicity when encountering complicated optimization problems. The optimization approaches in hybrid hydro-solar-wind systems is presented in Figure 2. The main objective is to analyze the capacity of such a system to be able to store the excess of wind/solar energy, at times when energy demand is lower, and provide reserves in the form of hydropower at times when consumption exceeds the wind/solar production or, alternatively, making the system self-sufficient. This model was developed for a time scale of one average year, assuming hourly variations, i.e., 8760 iterations, where dimensional data regarding variations in electricity demand and wind/solar energy production.

Figure 2 depicts the proposed framework to coordinate pumped-storage and wind-solar renewable energies, with a closed-loop dispatch process as follows.

The pumped hydro storage (PHS) is the energy storage solution in this study, consisting on a separated pump/motor unit and a turbine/generator unit to manage the other renewable sources inputs to face the energy demand [28]. The turbine generating coefficient $\left(\mathrm{kWh} / \mathrm{m}^{3}\right)$ in Equation (1) and the water pumping coefficient $\left(\mathrm{m}^{3} / \mathrm{kWh}\right)$ in Equation (2) are two key parameters of the PHS elements. According to $[29,30]$ the following equation describes the total stored energy $E^{t}$ (in $\mathrm{kWh}$ ) in the active volume of a reservoir:

$$
E^{t}=\eta_{t} \times \rho \times g \times H \times V=c_{t} \times V \quad(\mathrm{kWh}),
$$


where $H$ is the net head $(\mathrm{m}), \eta_{t}$ the overall efficiency of the turbine/generator unit (\%), $V$ the storage capacity $\left(\mathrm{m}^{3}\right), c_{t}$ is the turbine generating coefficient $\left(\mathrm{kWh} / \mathrm{m}^{3}\right), g$ is the acceleration due to gravity $\left(\mathrm{m} / \mathrm{s}^{2}\right), \rho$ is the density of the water $\left(\mathrm{kg} / \mathrm{m}^{3}\right)$.

The energy used to pump the water volume to a specific height, with a specific pumping efficiency is given by

$$
E^{p}=\frac{\rho \times g \times H \times V}{\eta_{p}}=c_{p} \times V \quad(\mathrm{kWh}),
$$

where $H$ is the pumping head $(\mathrm{m}), \eta_{p}$ is the overall pumping efficiency $(\%)$, and $c_{p}$ is the water pumping coefficient of the pump/motor unit $\left(\mathrm{m}^{3} / \mathrm{kWh}\right)$.

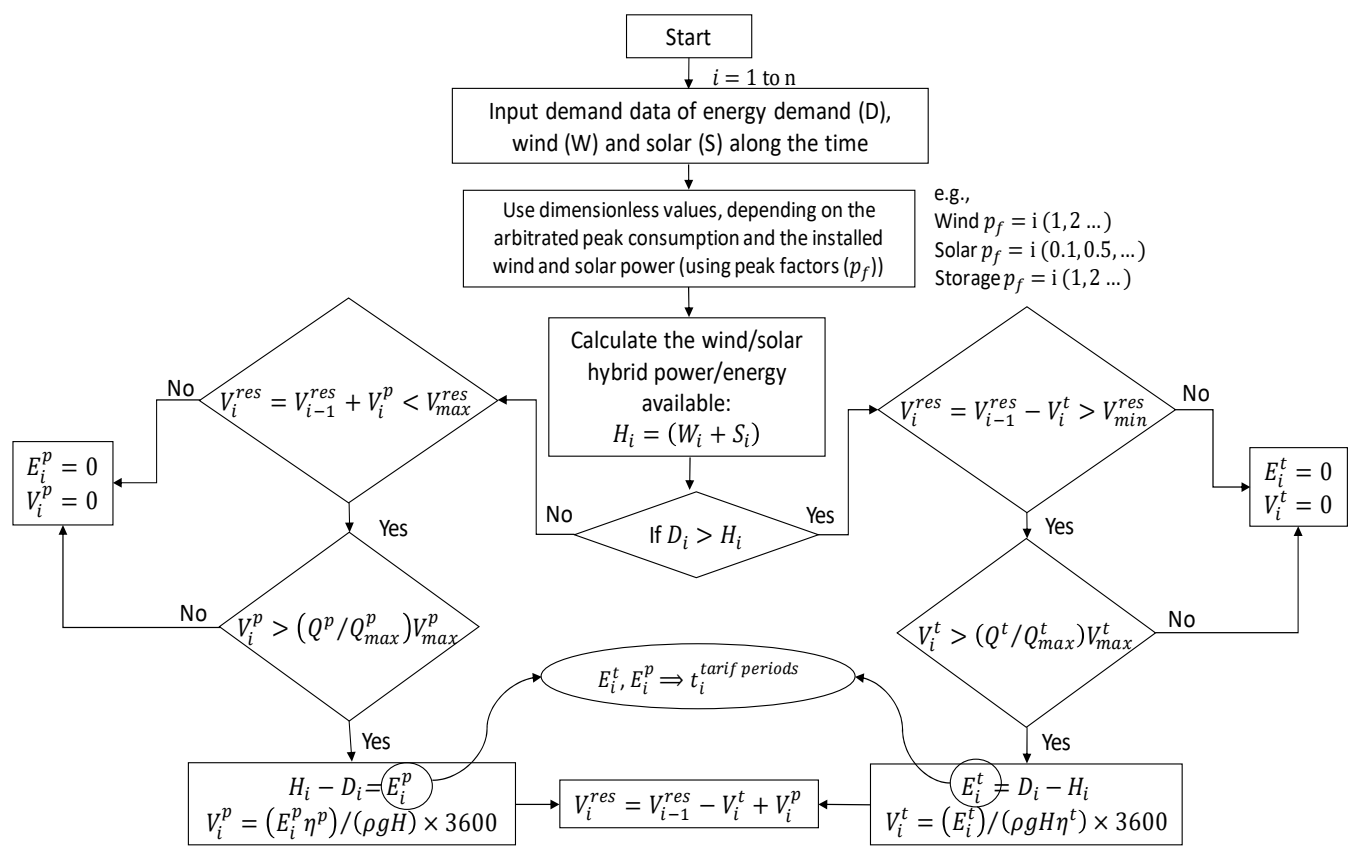

Figure 2. Flowchart to find optimal hybrid system. $V$ is for water volume, $E$ is for energy, $D$ is the demand, $H$ is for hybrid power/energy available, $S$ is the solar energy and $W$ is for wind energy. The superscripts $(p, t, r e s)$ are assigned for pump, turbine and reservoir.

In the case of energy deficits, water is drawn from the upper reservoir in order to operate the hydro turbines.

Finally, the proposed dispatch model selects the best combination of peak factors to reach the optimal solution in terms of efficiency, energy exploitation, cost, and footprint. The peak factor is the ratio of the total flow to the average daily flow in a water system and is important in the study of a water system to determine potential water consumption values. The ratio of the total flow for large water systems generally varies from 1.2 to 3.0 or even higher for specific small systems [31].

\subsubsection{Operating Principles and Important Restrictions}

The pumping process is done during the empty hours (i.e., of lower demand) and the hydroelectric generation through peak hours (i.e., for highest demand). Thus, the consumption during the off-peak hours was satisfied exclusively by wind/solar, while in the remaining period, the power generation is complemented by hydro, if insufficient wind/solar production is verified. Excess wind/solar energy that is not used for consumption in the system is used for pumping. In this way, it is possible to reduce the purchase costs of electricity from the grid. The respective operating conditions Equation (3) and restrictions Equation (4) are described below: 
Operating conditions:

$$
\begin{gathered}
V_{\text {min }}^{\text {res }}>0.15 V_{\max }^{\text {res }} \\
V_{i}^{\text {res }}=V_{i-1}^{\text {res }}+V_{i}^{p}-V_{i}^{t} \\
V_{i}^{p} \geq \frac{\stackrel{Q}{\text { min }}_{Q_{\text {max }}^{p}}^{p} V_{\max }^{p}, V_{i}^{t} \geq \frac{Q_{\min }^{t}}{Q_{\max }^{t}} V_{\max }^{t}}{\Delta E_{i}=H_{i}-D_{i}}
\end{gathered}
$$

Restrictions considered:

$$
\begin{gathered}
\text { If } V_{i}^{\text {res }} \geq V_{\max }^{\text {res }} \rightarrow V_{i}^{p}=0 \\
\text { Else } V_{i}^{p}=\left(E_{i}^{p} \eta^{p}\right) /(\rho g H) \times 3600 \\
\text { If } V_{i}^{\text {res }} \leq V_{\min }^{\text {res }} \rightarrow V_{i}^{t}=0 \\
\text { Else } V_{i}^{t}=\left(E_{i}^{t}\right) /\left(\rho g H \eta^{t}\right) \times 3600 \\
\text { If time }=\text { offpeak period } \rightarrow E_{i}^{p}=\text { Pump power installed, } E_{i}^{t}=0 \\
\text { Else } E_{i}^{p}=0, E_{i}^{t}=-\Delta E_{i}
\end{gathered}
$$

\subsubsection{Daily Cycle for Electricity Supply}

According to Figure 2, $E_{i}^{t}, E_{i}^{p}$ depend on the tri-time tariff (Table 1). As the pumping system works in the early hours of the day $(0-7 \mathrm{~h})$ the system presents sufficient reserves to be able to assist intermittent renewable energy production failures during the remaining period. The daily cycle for electricity supply, dictated by the tri-time tariff applied in mainland Portugal, is described in Table 1.

Table 1. Time-of-day tariff periods (weekly cycle).

\begin{tabular}{cccc}
\hline Days & Tarif Period & Winter & Summer \\
\hline \multirow{3}{*}{ Workdays } & Peak & $5 \mathrm{~h} /$ day & $3 \mathrm{~h} /$ day \\
& Half-peak & $12 \mathrm{~h} /$ day & $14 \mathrm{~h} /$ day \\
& Normal off-peak & $3 \mathrm{~h} /$ day & $3 \mathrm{~h} /$ day \\
& Super off-peak & $4 \mathrm{~h} /$ day & $4 \mathrm{~h} /$ day \\
\hline \multirow{2}{*}{ Saturdays } & Half-peak & \multicolumn{2}{c}{$7 \mathrm{~h} /$ day } \\
& Normal off-peak & \multicolumn{2}{c}{$13 \mathrm{~h} /$ day } \\
& Super off-peak & $4 \mathrm{~h} /$ day \\
\hline \multirow{2}{*}{ Sundays } & Normal off-peak & \multicolumn{2}{c}{$20 \mathrm{~h} /$ day } \\
& Super off-peak & \multicolumn{2}{c}{$4 \mathrm{~h} /$ day } \\
\hline
\end{tabular}

\section{Case Study}

\subsection{Modelling Assumptions}

The benefit in using medium-head pumped-storage plants is to shorten transmission lines from the alternative energy sources to the hydro storage facility, thus minimizing grid overloading due to energy transfer across a country [32]. Moreover, it has the advantage of locating wind or solar farms close to hydropower schemes, which are usually installed in higher topographic zones [33-36].

The proposed solution focuses on a converter connected to a motor/generator. The mostly used is the pump as turbine (PAT) type that allows variable speed to cover the required operating range in both modes of operation. The efficiency considered can vary between $70 \%$ and $80 \%$ for pump/turbine mode, respectively. The overall energy storage system efficiency is $56 \%$, corresponding to a water pumping and turbine generating coefficients of $1.837 \mathrm{~m}^{3} / \mathrm{kWh}$ and $0.305 \mathrm{kWh} / \mathrm{m}^{3}$, respectively. The energy converter pump as turbine is of variable speed, which allows the exploitation of excess energy produced by PV arrays and wind turbines and also allows covering medium load by a remaining part of hydropower, to improve the overall energy system efficiency.

For both designs, the load profiles and the meteorological data were collected from [37], where the wind power distribution and the solar radiation are presented in Figures 3 and 4, respectively. 
Data were collected from meteorological records at a wind and solar power stations located at the geographical coordinates of $38^{\circ} 47^{\prime} 4^{\prime \prime} \mathrm{N}$ (latitude) and $9^{\circ} 29^{\prime} 26^{\prime \prime} \mathrm{W}$ (longitude), for an average year. Then, dimensionless values were used, depending on the arbitrated peak consumption values and the installed wind and solar energies.

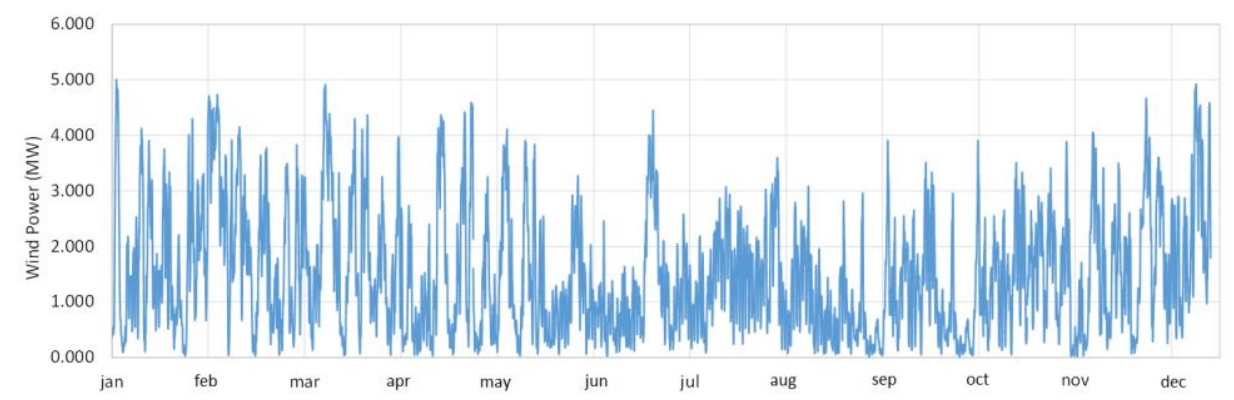

Figure 3. Average wind power distribution during an average year [28].

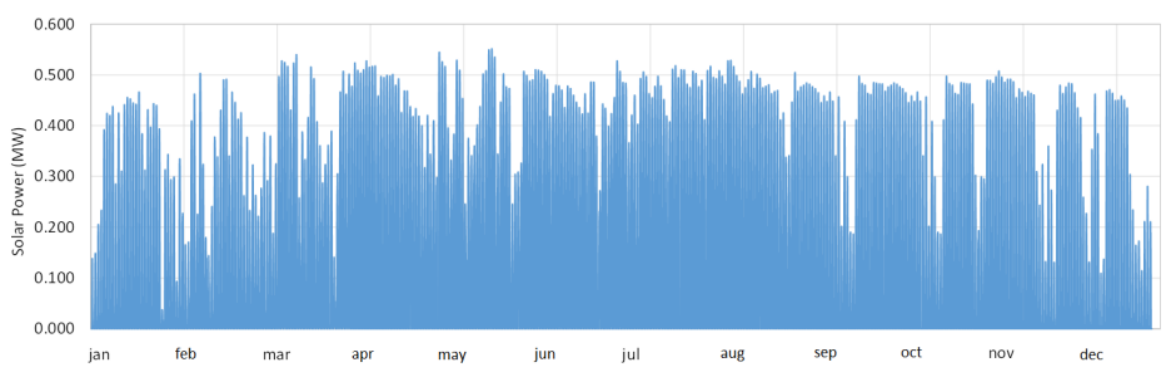

Figure 4. Average solar power distribution during an average year [28].

To demonstrate the contributions when combining pumped hydro storage (PHS) and hydro-wind-solar power system, several analyses were made, considering a peak consumption of $4 \mathrm{MW}$, and pump/turbine of 2, 4 and $6 \mathrm{MW}$, respectively. Hence, Figure 5 shows the schematic diagram of all different combinations used: total satisfied consumption and what part is supplied only by the PHS (depending on the installed power for each renewable sources), through wind + hydro and solar + hydro for different storage volumes. Analyzing wind + hydro, it is clear that the storage values considerably influence the satisfaction of demand. For the combination of solar and hydropower, this is not so visible, especially for higher storage values.

The use of wind or solar power as the source of energy supply may not be sufficient to meet the demand without a PHS. On the contrary, the higher the ratio between the installed wind energy and the peak consumption, the higher the satisfied consumption. However, although the wind energy proved to be more effective with a significant increase in the consumption satisfaction, it also translated into a greater surplus and from there the need to integrate a storage system capable of harnessing unused energy [37-39]. Combining the three sources (Figure 6) with an installed PAT of $4 \mathrm{MW}$ allows to reach levels of satisfied consumption of 70 to $85 \%$, with high annual complementarity, against $60-80 \%$, when using $\mathrm{P} / \mathrm{Ts}$ with $6 \mathrm{MW}$ and $40-60 \%$ for $\mathrm{P} / \mathrm{Ts}$ with $2 \mathrm{MW}$.

According to Figure 6, four scenarios related to each $\mathrm{P} / \mathrm{T}$ stand out based on the best combination between the three available renewable sources (Table 2). For these, an estimation of costs and associated profits as a function of the installed power was made where it was assumed that the turbomachines cost corresponds to $35 \%$ of the total PHS and that the cost related to the wind presents a linear variation of about $583 € / \mathrm{MW}$ of installed power. The profit from the purchase and sale of electricity to the national grid was accounted through the relative data of the tri-time price rate applied in Portugal mainland (Table 3). 


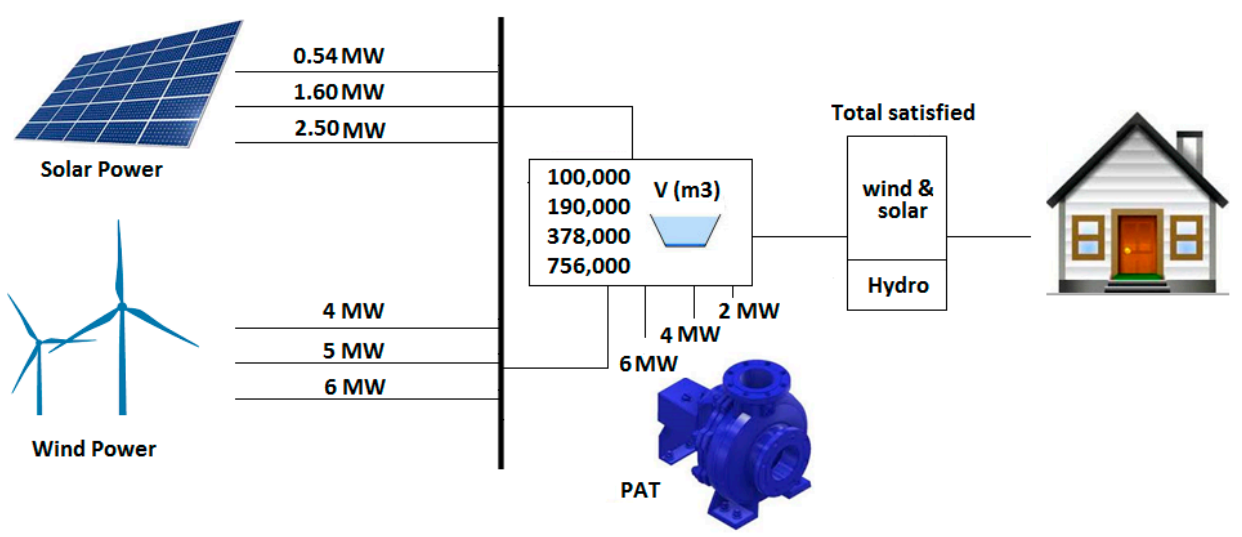

(a)
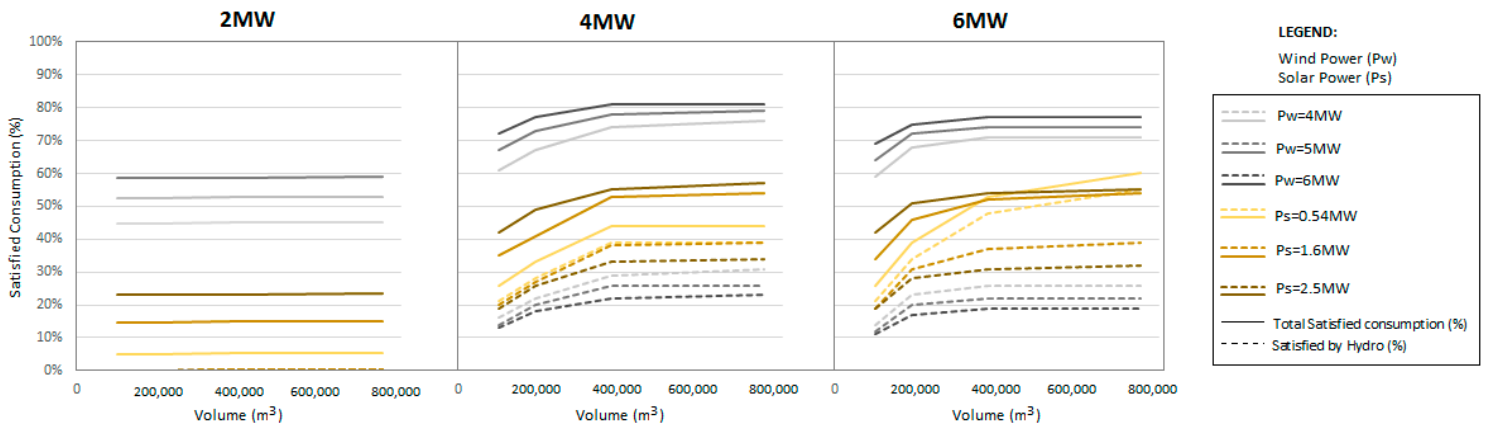

(b)

Figure 5. Hybrid solution: shematic diagram of different combinations used (a); satisfied demand (wind + hydro; solar + hydro; hydro) for different pump as turbine (PAT)'s power (b).

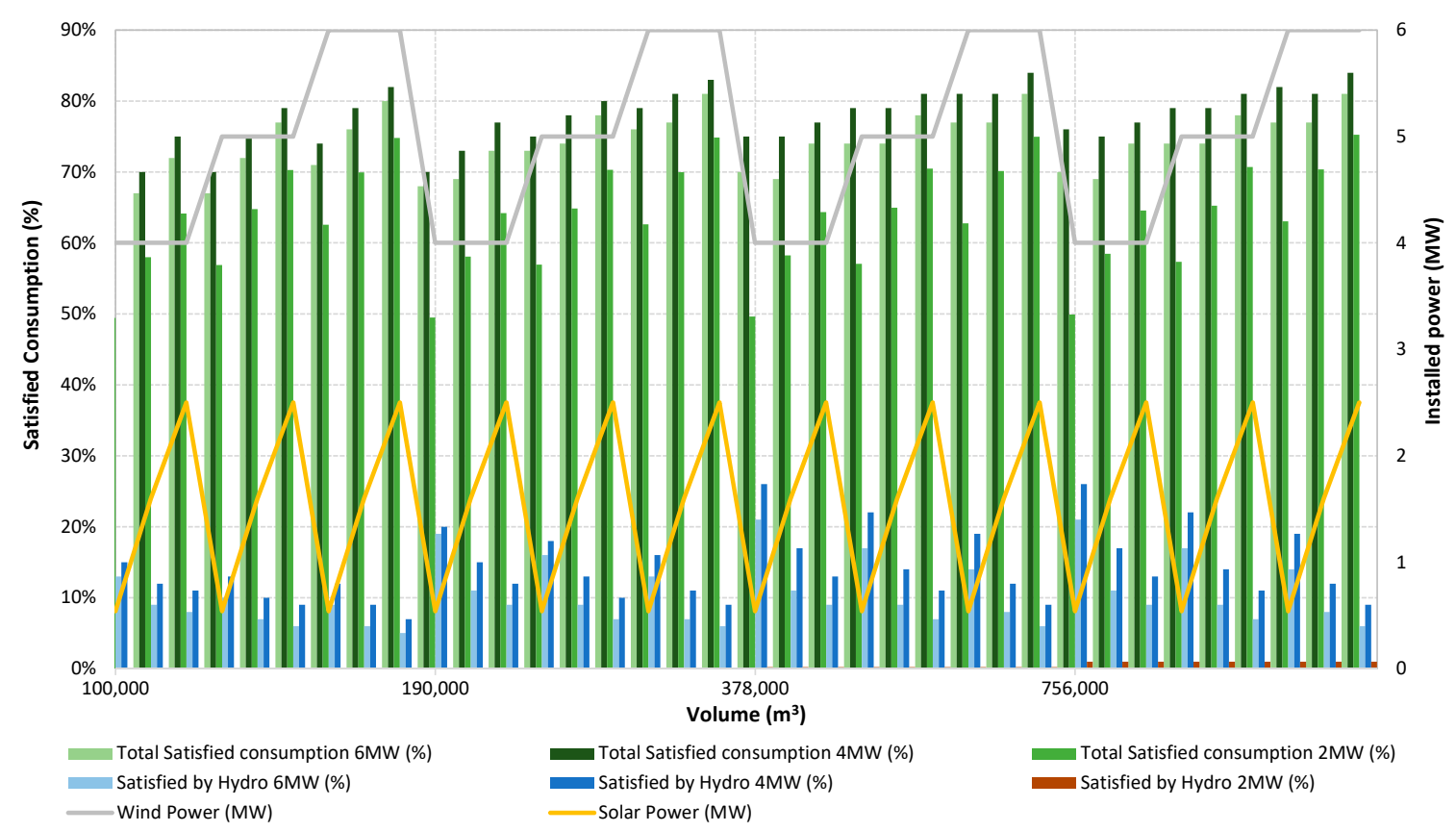

Figure 6. Satisfied consumption (wind + solar + hydro; hydro) using P/Ts with 6, 4 and $2 \mathrm{MW}$. 
Table 2. Estimation of costs and associated profits as a function of the installed power.

\begin{tabular}{|c|c|c|c|c|c|c|c|c|}
\hline $\mathrm{V}\left(\mathrm{m}^{3}\right)$ & $\begin{array}{c}\text { Pw } \\
\text { (MW) }\end{array}$ & $\begin{array}{c}\mathbf{P}_{\mathbf{P} / \mathrm{T}} \\
\text { (MW) }\end{array}$ & $\mathrm{Cw}(\boldsymbol{\epsilon})$ & $\mathrm{C}_{\mathrm{P} / \mathrm{T}}(€)$ & $\mathrm{C}_{\text {PHS }}(\boldsymbol{\epsilon})$ & Total (€) & Profit (€) & $\begin{array}{l}\text { Return } \\
\text { (Years) }\end{array}$ \\
\hline 378,000 & 4 & \multirow{4}{*}{6} & $2,333,320$ & \multirow{4}{*}{303,834} & \multirow{4}{*}{835,544} & $3,168,864$ & 282,336 & 11.2 \\
\hline 378,000 & 5 & & $2,916,650$ & & & $3,752,194$ & 299,948 & 12.5 \\
\hline 756,000 & 4 & & $2,333,320$ & & & $3,168,864$ & 281,997 & 11.2 \\
\hline 756,000 & 5 & & $2,916,650$ & & & $3,752,194$ & 299,601 & 12.5 \\
\hline 378,000 & 4 & \multirow{4}{*}{4} & $2,333,320$ & \multirow{4}{*}{200,034} & \multirow{4}{*}{550,094} & $2,883,414$ & 357,336 & 8.1 \\
\hline 378,000 & 5 & & $2,916,650$ & & & $3,466,744$ & 365,525 & 9.5 \\
\hline 756,000 & 4 & & $2,333,320$ & & & $2,883,414$ & 360,530 & 8.0 \\
\hline 756,000 & 5 & & $2,916,650$ & & & $3,466,744$ & 366,695 & 9.5 \\
\hline
\end{tabular}

Pw-Wind Power; $\mathrm{P}_{\mathrm{P} / \mathrm{T}}$-Pump/Turbine Power.

Table 3. Tariff rate applied in Portugal mainland $(€)$.

\begin{tabular}{cccc}
\hline Peak & Half-Peak & Off-Peak & Super Off-Peak \\
\hline 0.097 & 0.0406 & 0.0115 & 0.0115 \\
\hline
\end{tabular}

Table 2 shows the investment costs and gross benefit estimation depending on each selected solution presented in Figure 6.

The results from Table 3, reveal that the use of P/Ts with $6 \mathrm{MW}$ do not present any advantage over the P/Ts with $4 \mathrm{MW}$, using the same wind energies. Concluding, P/TS with $4 \mathrm{MW}$ are economically viable, offering the best technical alternative at the lowest cost, with less return on the investment.

Nevertheless, to understand the relevant aspects of the joint action of these three solutions in consumer satisfaction needs, the energy contribution of four hybrid solutions (based on Table 3) over an average year was studied, assuming the characteristics described in Table 4.

Table 4. Selected scenarios.

\begin{tabular}{cccccc}
\hline Scenarios & $\begin{array}{c}\text { Peak } \\
\text { Consumption }\end{array}$ & $\begin{array}{c}\text { Wind } \\
\text { Power }\end{array}$ & $\begin{array}{c}\text { Solar } \\
\text { Power }\end{array}$ & $\begin{array}{c}\text { Pump/ } \\
\text { Turbine }\end{array}$ & Storage \\
\hline Scenario 1 & & $4 \mathrm{MW}$ & $0.54 \mathrm{MW}$ & $4 \mathrm{MW}$ & $144 \mathrm{MWh}\left(378,000 \mathrm{~m}^{3}\right)$ \\
Scenario 2 & $4 \mathrm{MW}$ & $5 \mathrm{MW}$ & $0.54 \mathrm{MW}$ & $4 \mathrm{MW}$ & $144 \mathrm{MWh}\left(378,000 \mathrm{~m}^{3}\right)$ \\
Scenario 3 & & $5 \mathrm{MW}$ & $0.54 \mathrm{MW}$ & $4 \mathrm{MW}$ & $240 \mathrm{MWh}\left(755,685 \mathrm{~m}^{3}\right)$ \\
Scenario 4 & & $5 \mathrm{MW}$ & $1.60 \mathrm{MW}$ & $4 \mathrm{MW}$ & $144 \mathrm{MWh}\left(755,685 \mathrm{~m}^{3}\right)$ \\
\hline
\end{tabular}

In all cases, two reservoirs (i.e., upper and lower reservoirs) were considered, with the initial volume of the upper reservoir at $50 \%$ of its maximum capacity to allow the system to pump or turbine within the first hour.

\subsection{Results}

\subsubsection{Scenario 1}

The power grid and energy storage in Figure 7 (for winter months of February and March) and Figure 8 (for summer months August and September) represent the power and energy variables for the time-line modelled: (i) curves of power demand, wind, solar, hydro and pump (left y-axis); (ii) curve for the storage volume by water pumped into the upper reservoir (right y-axis). Herein, the storage water volume was designed for 1.5 days peak demand power. It can be observed the contribution of renewable sources fulfils the energy demand with more or less effect of pump-storage solution to harmonize the available energy at each instant depending on the summer or winter period analyzed. 
For the characteristics defined in Table 4, the system satisfies 15.37 GWh, where 19\% comes from hydro and $49 \%$ from wind and solar, with an annual maximum wind power of $1.25 \times$ peak demand and solar power of $0.135 \times$ peak demand. The sources pattern varies, and the consumption satisfaction adapts to the sources' availability as function of the power selected to be installed. Even if it seems to have a low share of hydro level source, it is essential to keep flexibility and sustainability performance levels.

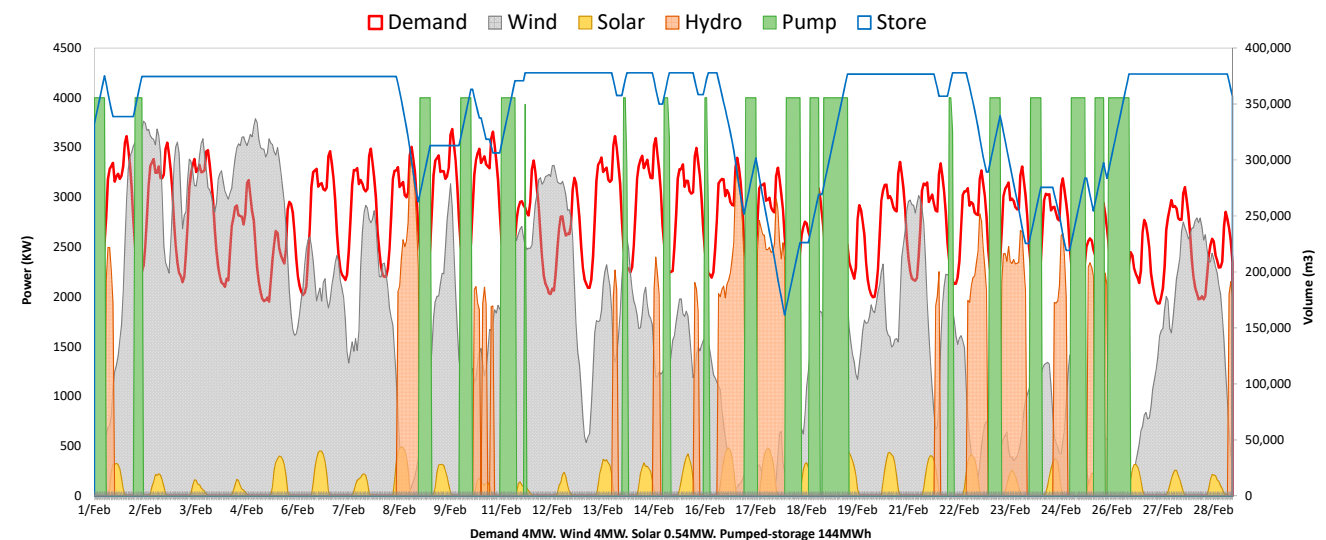

(a)

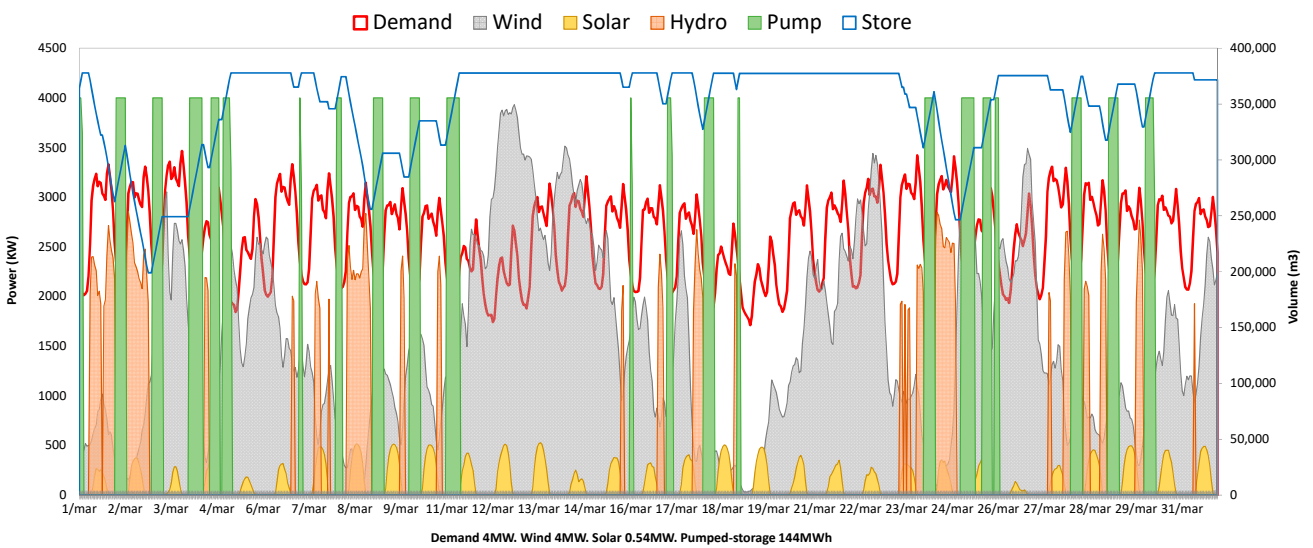

(b)

Figure 7. Electricity generation (Wind, PV and Pumped-Storage Hydro) between February (a) and March (b).

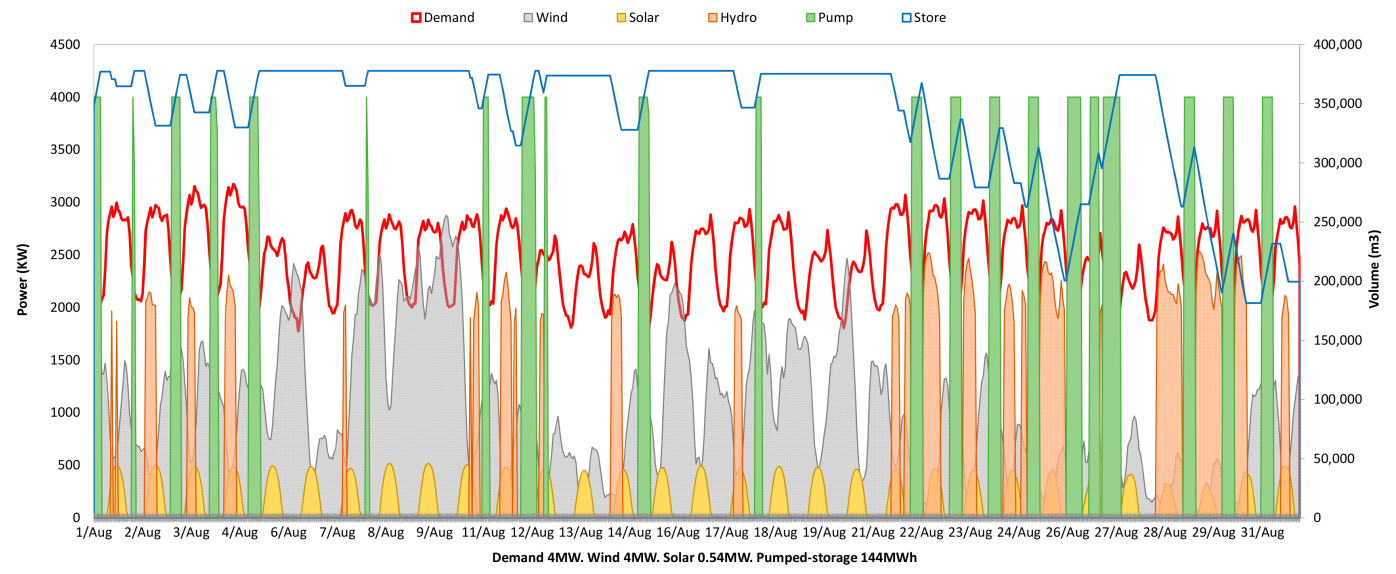

(a)

Figure 8. Cont. 


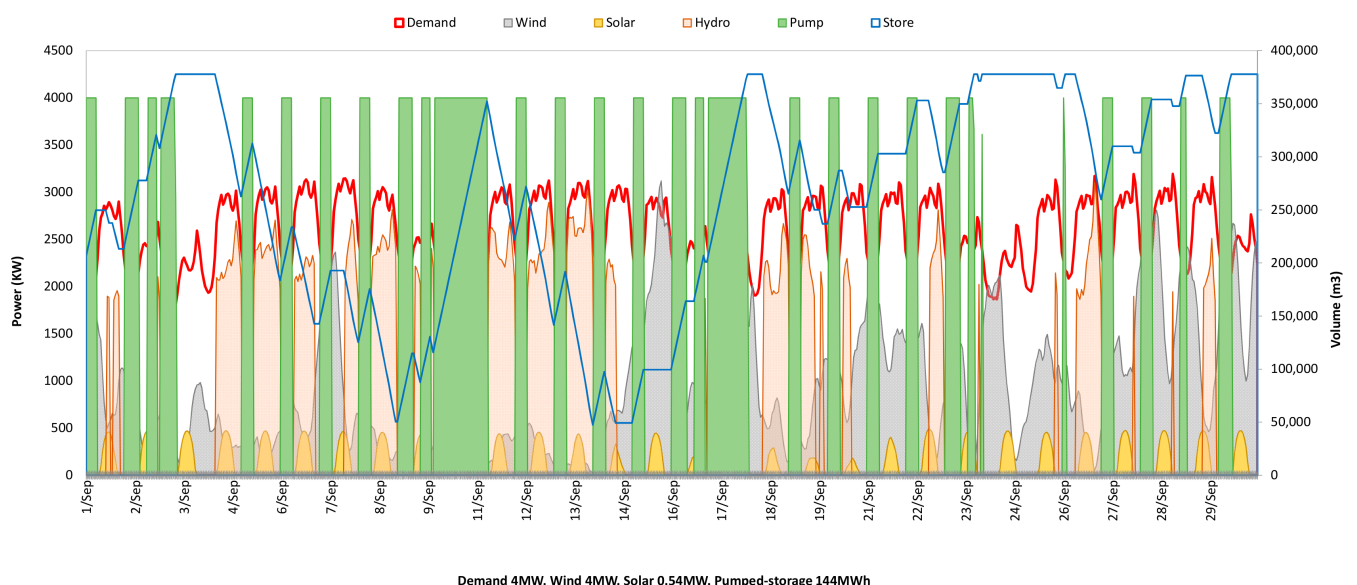

(b)

Figure 8. Electricity generation (Wind, PV and Pumped-Storage Hydro) between August (a) and September (b).

\subsubsection{Scenario 2}

The next power grid and energy storage timelines (Figures 9 and 10) illustrate when the wind power is $5 \mathrm{MW}$. Herein, the system produces $3.41 \mathrm{GWh}$ of hydropower responsible for satisfying $15 \%$ from the $72 \%$ of the total satisfied consumption; the remaining power is guaranteed through wind and solar energies.

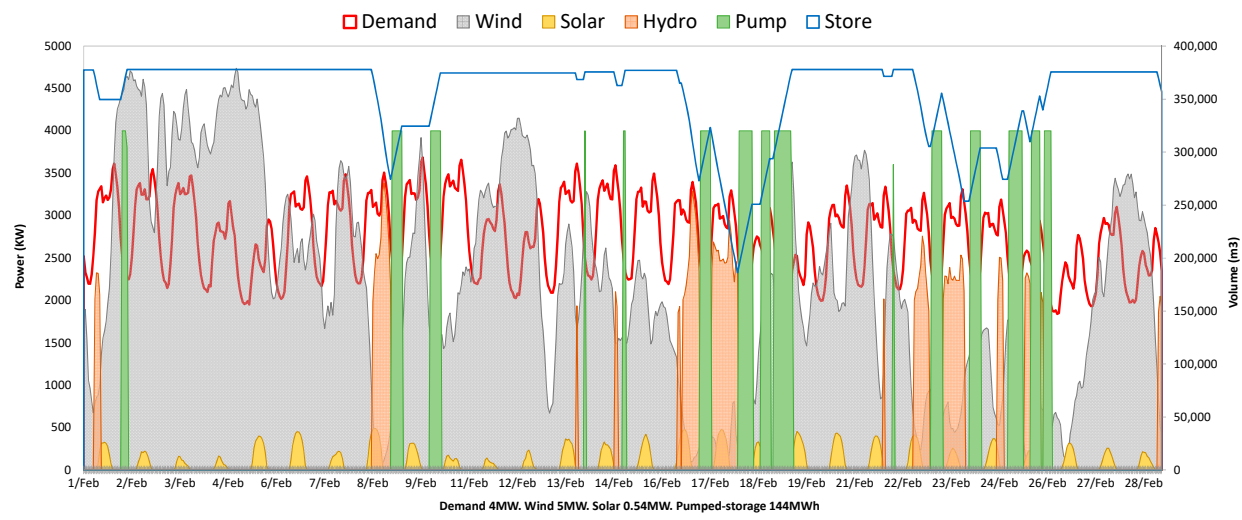

(a)

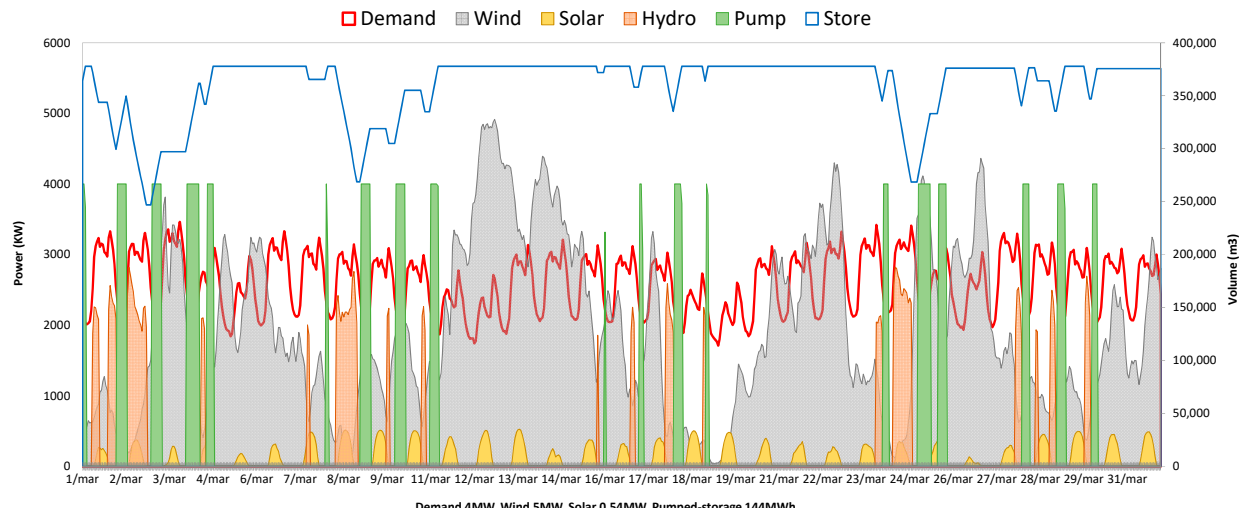

(b)

Figure 9. Electricity generation and stored in scenario 2 between February (a) and March (b). 


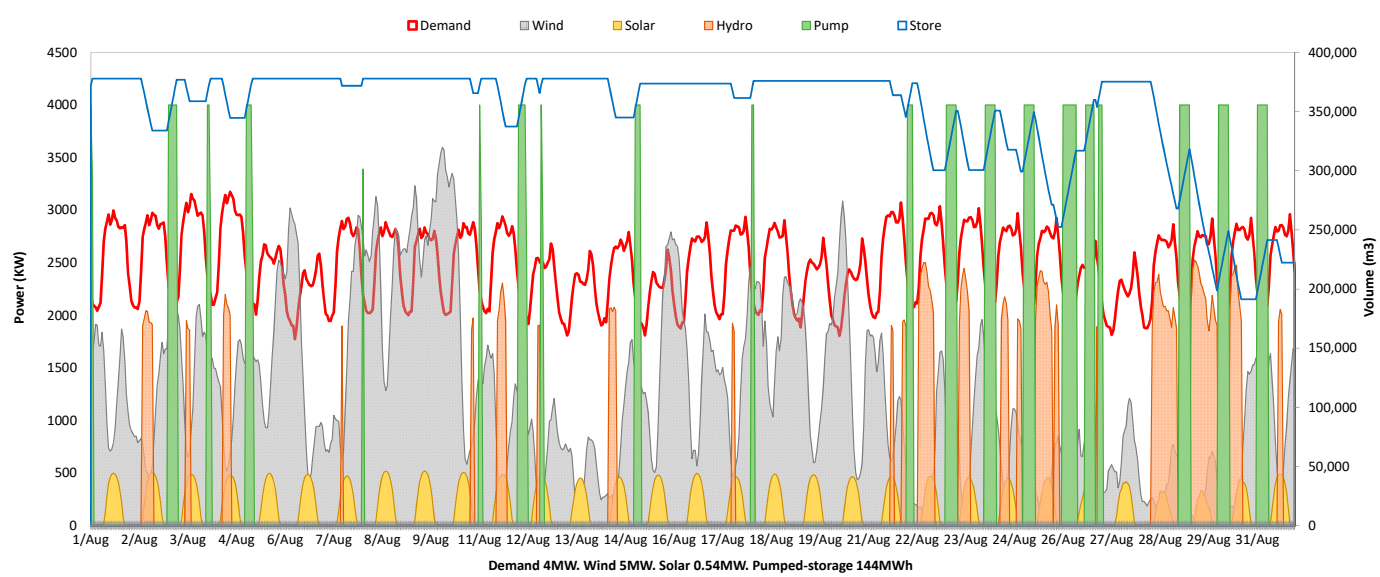

(a)

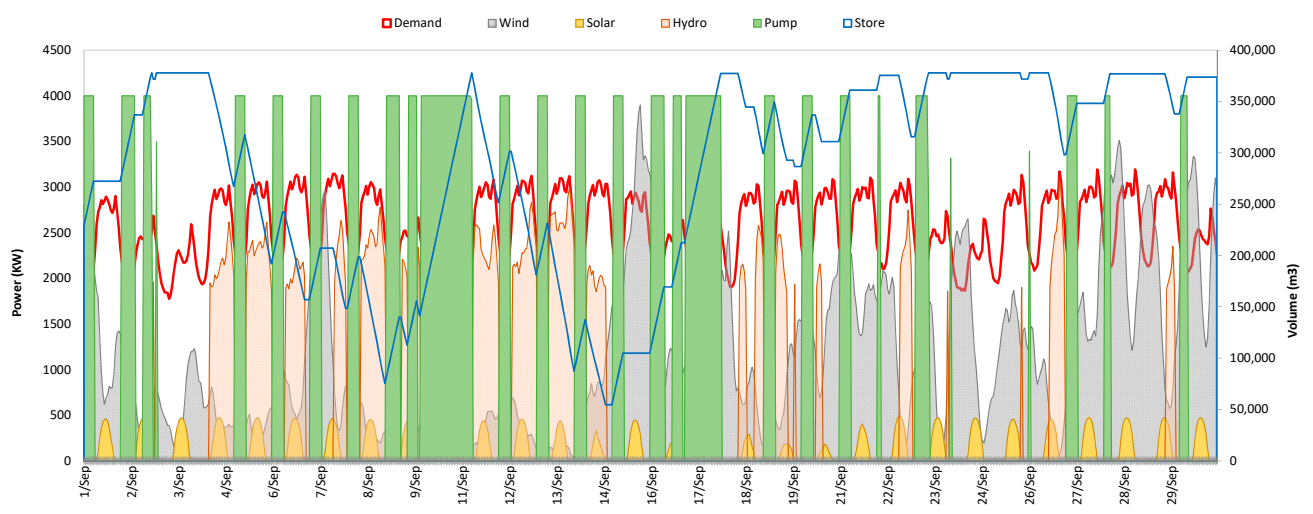

(b)

Figure 10. Electricity generation and stored in scenario 2 between August (a) and September (b).

It is notable that increasing the wind power, the hydropower production decreases accordingly. Figure 11 shows the total amount of energy that could be easily harnessed through hydropower in scenario 2, the use of this energy to overcome the wind failures and how excess of wind production in some periods can be used for pumping, creating water reserve for the period of highest consumption. The uniformity of the available sources and storage capacity makes the system more robust.

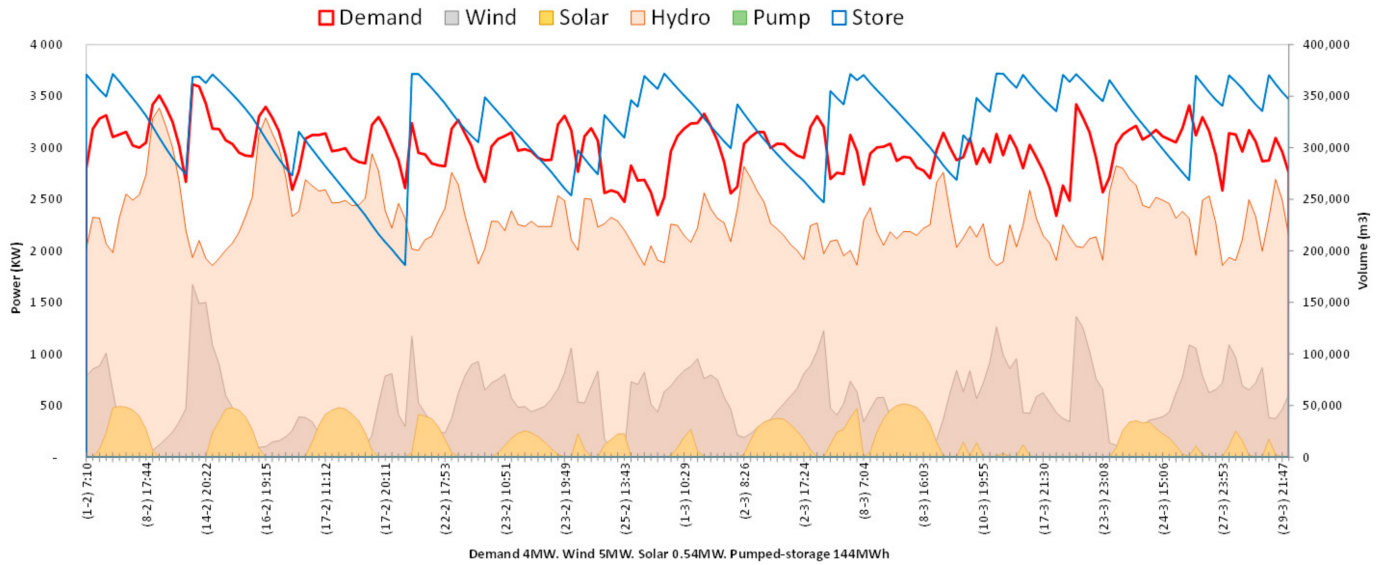

(a)

Figure 11. Cont. 


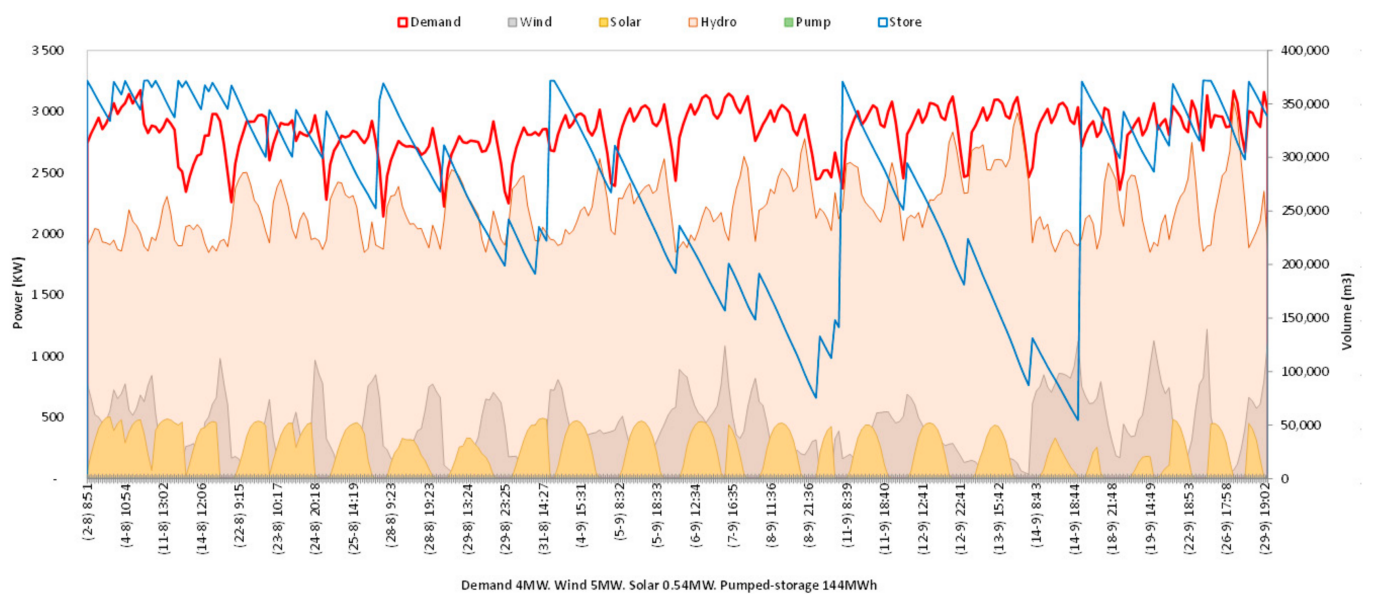

(b)

Figure 11. Total amount of hydropower when using wind energy with $5 \mathrm{MW}$, between February and March (a) and August-September (b).

Thus, by increasing the installed maximum wind power from $4 \mathrm{MW}$ up to $5 \mathrm{MW}$, it is possible to take advantage of a few hours more efficiently, if the power line transmission capacity between the wind generators and the pumps exceeds the peak demand. The storage is adapted to the wind power availability allowing a better compensation between resources.

\subsubsection{Scenario 3}

In scenario 3, the volume of storage was increased up to $755,685 \mathrm{~m}^{3}$ ( 2 times the initial one). The amount of energy that is satisfied by hydro is practically the same, comparing to scenario 2 since the volume used depends on the demand that was kept constant. With this scenario, it is possible to feel the influence or not in some parameters depending on how the intervenient variables are optimized and integrated in a more flexible solution (Figure 12).

Thus, the increasing of the volume storage does not contribute significantly, only $0.56 \%$ of the hybrid energy is used to pump. Thus, a balance needs to be made between the total energy that is needed for the best functioning of the PHS, in terms of sources management and the technical level, as well as the investment cost, operation and maintenance cost of this system and also the risk-return profile, in terms of economic performance.

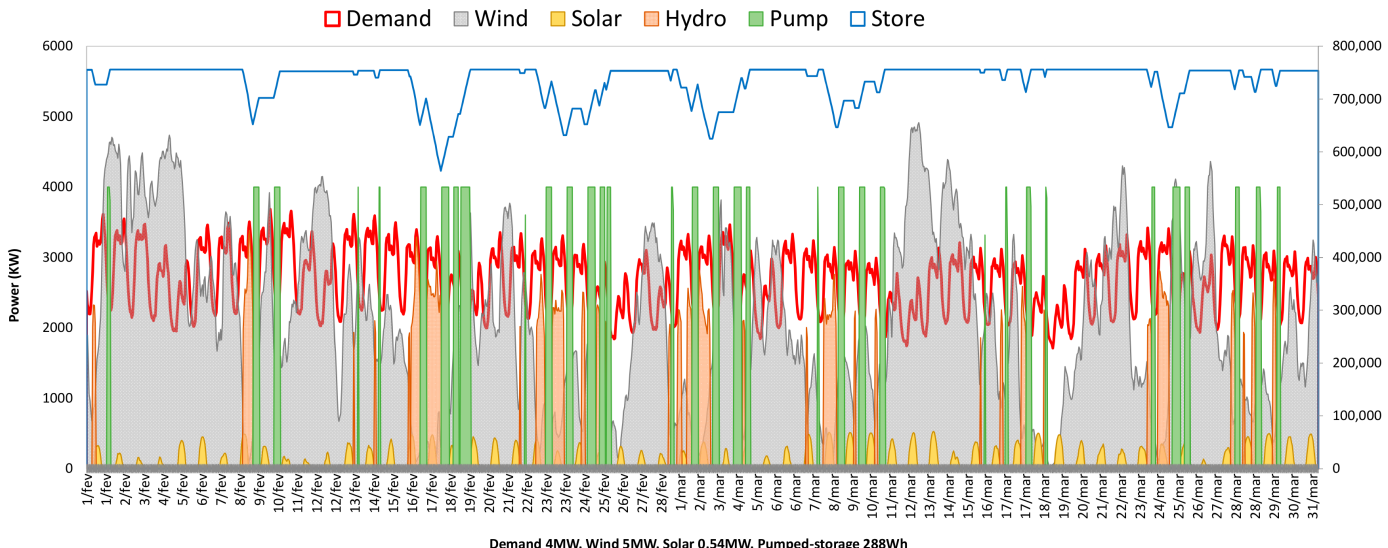

(a)

Figure 12. Cont. 


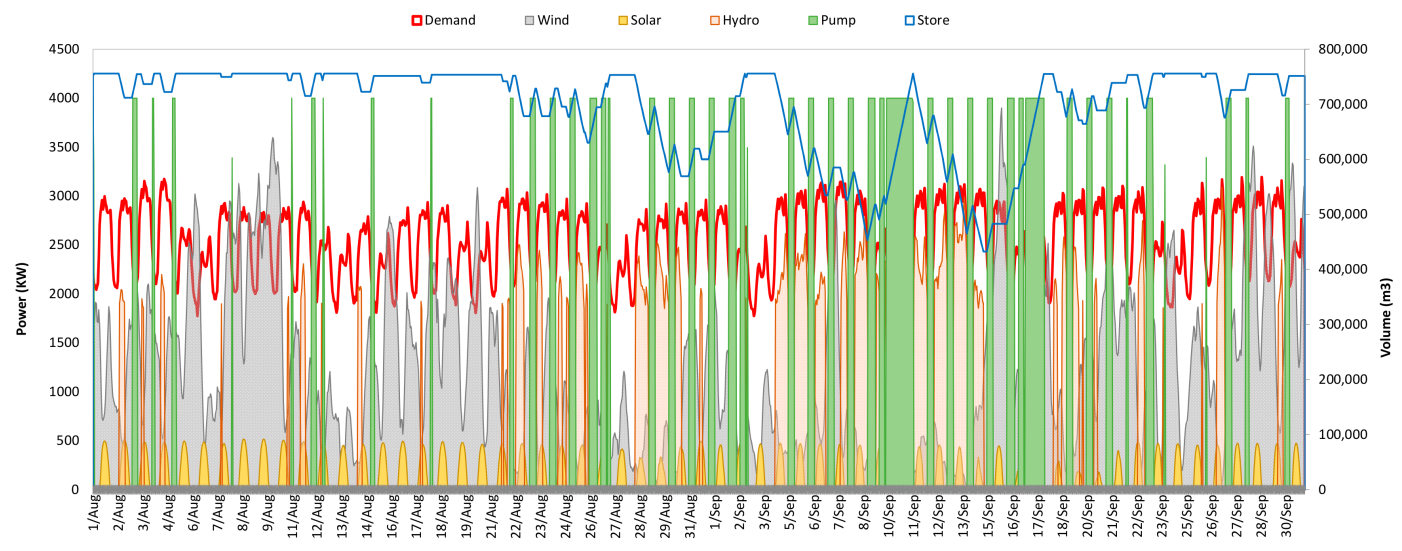

(b)

Figure 12. Electricity generation and stored in scenario 3, between February and March (a) and August and September $(\mathbf{b})$.

\subsubsection{Scenario 4}

In Scenario 4 the PV power is increased up to 1.6, i.e., using a peak factor of 2.96 times the previous one (0.135) (Figure 13).

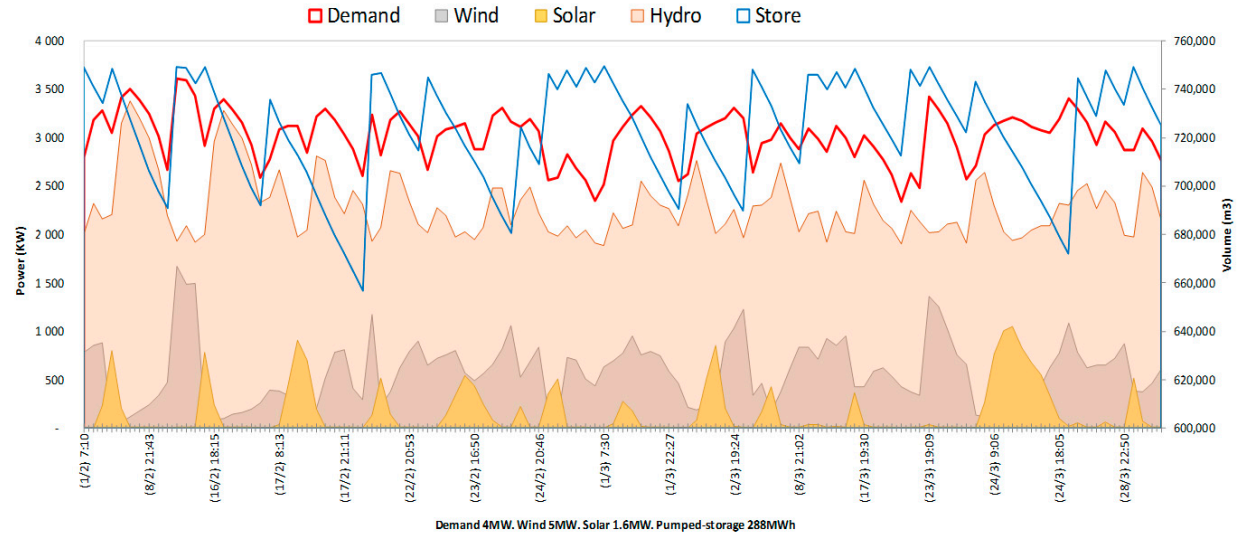

(a)

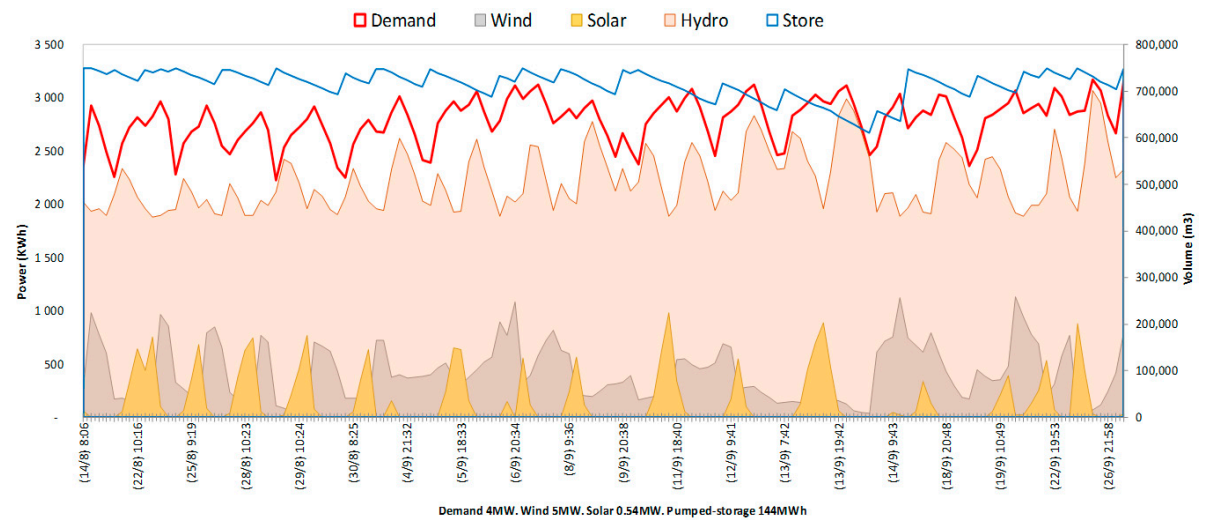

(b)

Figure 13. Total amount of energy stored vs demand in scenario 4, between February and March (a) and August and September (b). 
The total energy used for consumption was $16.42 \mathrm{GWh}$, representing $73 \%$, where only $8 \%$ comes from hydro and the remaining from wind and solar solutions. However, by increasing the solar energy, $11 \%$ of this energy is wasted (i.e., $2 \%$ more comparing with scenario 2 ), and only $1 \%$ more contributes to the satisfied consumption. Again, the evidence of this sensitivity analysis focused on the increasing power for some resources does not mean a better solution because this multivariate optimization requires several interpretations depending on the main use made of the available sources in each instant and for the analysed period. Having more solar energy imposes a reduction on the use of hydro, because hydro is available when it is more essential not depending on the intermittency of wind and solar, making an interesting balance between the use of sources.

\section{Energy Balance}

The chosen hybrid hydro-wind and solar power solution with installed capacities of 5 and $0.54 \mathrm{MW}$, respectively, $4 \mathrm{MW}$ of integrated pumped storage and $\mathrm{V}=378,000 \mathrm{~m}^{3}$ would ensure $72 \%$ annual consumption satisfaction. Figures 13 and 14 show for each scenario the energy contribution of the three renewable sources for typical summer and winter days, respectively. Although it is considered a relatively low installed solar power ( $1 / 5$ wind), this source can be very useful on summer days, especially in the middle of the day, when the wind slows and the solar radiation increases. However, although increasing the PV installed capacity ensures $65 \%$ of the consumption through wind + solar (Figures 14d and 15d), comparing with scenario 2 (Figures 14b and 15b), the hydropower can cover that difference with the pump/hydro power solution. For the majority of winter days, there is a surplus of wind production at the beginning of the day, taking advantage of reducing the energy costs for scheduled pumping in the morning. Additionally, for a storage capacity of $144 \mathrm{MWh}$ and $288 \mathrm{MWh}$, there is practically no significant contribution when comparing to other scenarios (Figures 14c and 15c).

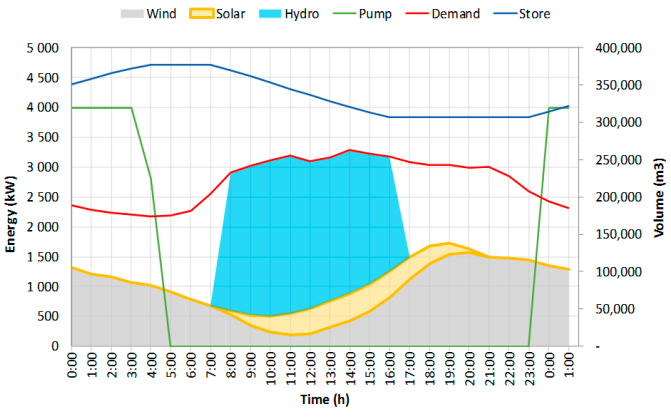

(a)

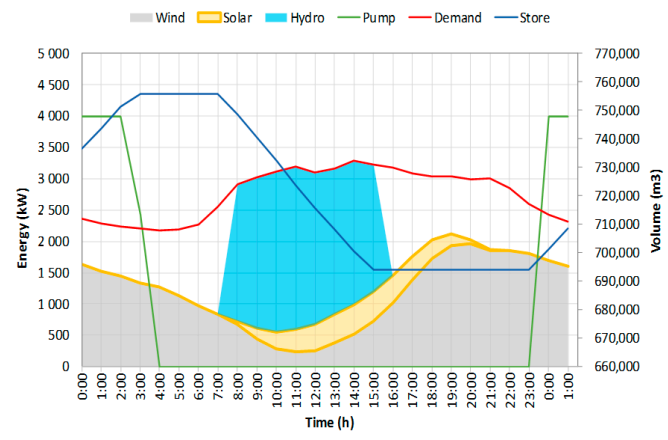

(c)

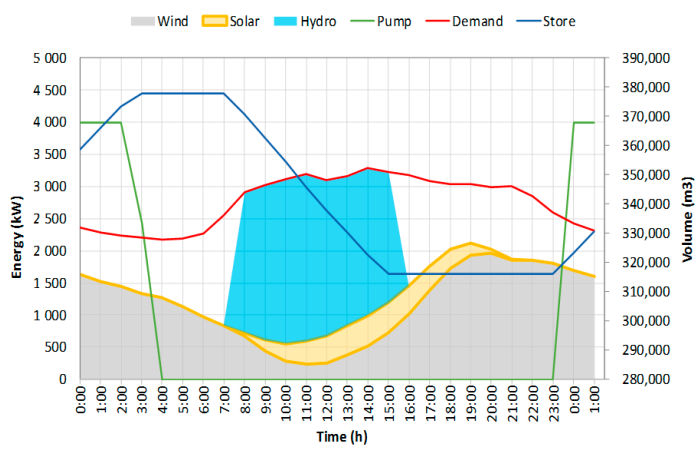

(b)

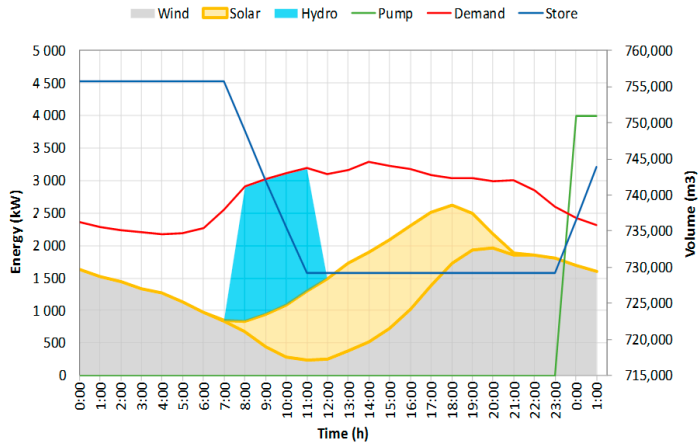

(d)

Figure 14. Energy contribution on summer day: (a) scenario 1; (b) scenario 2; (c) scenario 3; (d) scenario 4. 


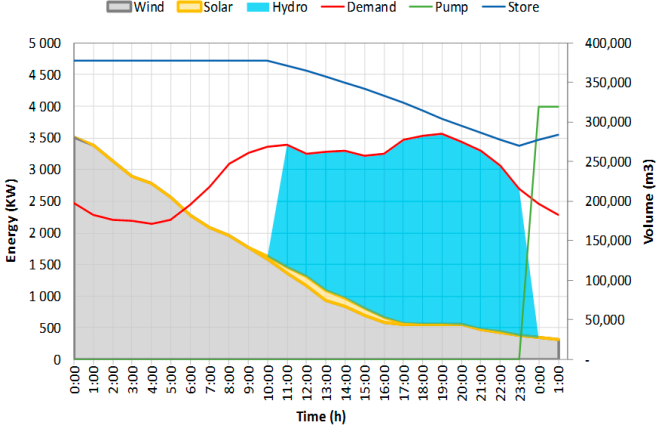

(a)

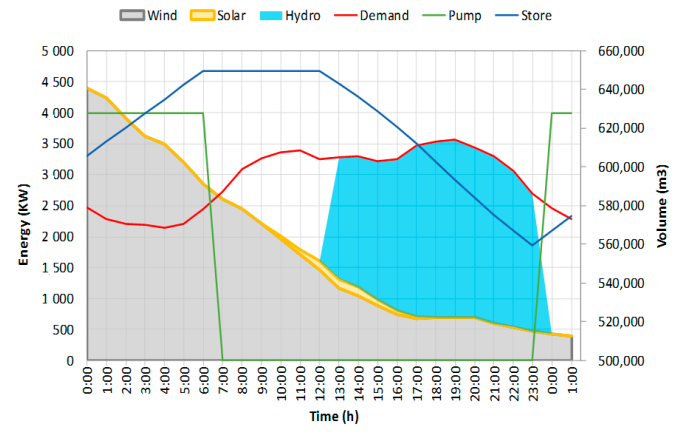

(c)

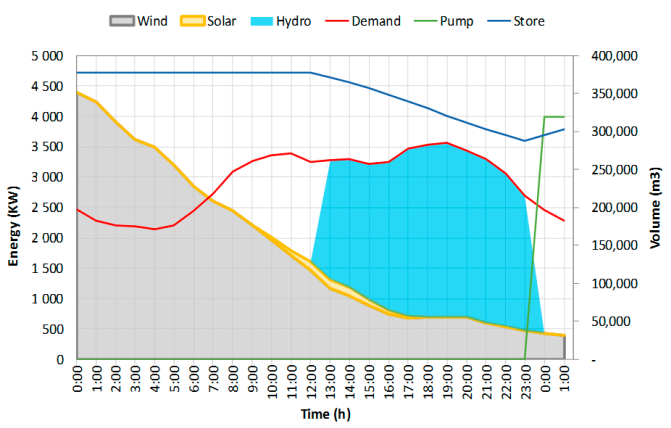

(b)

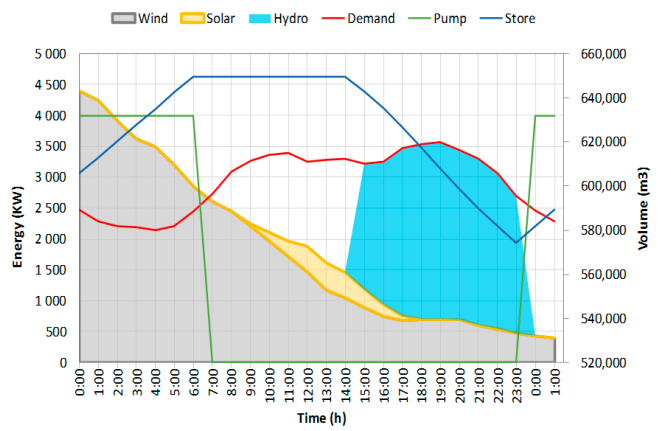

(d)

Figure 15. Energy contribution on a winter day: (a) scenario 1; (b) scenario 2; (c) scenario 3; (d) scenario 4.

It is important to verify that in all scenarios mostly in Figure $14 \mathrm{~d}$, between 12:00-23:00, the turbine volume is below the minimum turbine volume allowed; consequently, the system cannot operate during these hours even with a greater PV energy. Since this system does not depend on the excess of wind and solar energy, a better use of hydropower can be detected in scenario 1 (Figures 14a and 15a). However, it is important to remember that this operating solution needs to be connected to the grid, as the system cannot always be powered by wind/solar energy to perform pumping.

Thus, knowing that the peak demand and the average power is $4 \mathrm{MW}$ and therefore average daily usage only $24 \mathrm{~h} \times 4.0 \mathrm{MW}=96 \mathrm{MWh}$, for an optimized system, the hydropower energy capacity needed would be 1.5 times the maximum daily energy usage, assuming that the maximum wind and solar power is 0.056 per hour $x$ max daily energy usage. Thus, the annual maximum wind and solar power should be $5.4 \mathrm{MWh}$ and the energy store capacity $144 \mathrm{MWh}$ (i.e. $1.5 \times 96 \mathrm{MWh}$ ). Increasing the store capacity to $288 \mathrm{MWh}$, which is still a factor of 2 times more energy storage than the previous one (i.e., 1.5), does not contribute significantly to the operation of the system. This means that the reservoir may be oversized, as a large amount of reserves is not required to satisfy the consumption. Thus, this system depends not only on the maximum daily energy usage of the system but also on the hydropower system. Peak power demand does not completely specify a system's generation and storage requirements since both peak power and maximum daily energy usage are important design considerations.

The contribution of each energy source to the demand satisfaction was assessed (Figure 16) for the four scenarios (i.e., scenario 1, scenario 2, scenarios 3 and 4). It is clear that the storage values (between wind-hydro) considerably influence the satisfaction of consumption. In the combination of solar and hydropower, this is not so visible, especially for higher storage values. In each scenario, the wind energy demonstrates superior efficiency as there is not a large discrepancy between the maximum and minimum generation values. For scenario 1 (Figure 16a), the hydropower contribution presents a greater contribution compared with other scenarios, translating into a bigger unsatisfied demand, with less wind/solar energy impact. In scenario 2, by increasing the wind/solar power, the satisfied consumption through this energy source increases up to $4 \%$ compared to the previous one. Still, 
a water reserve storage system with a capacity twice the initial one brings no advantage (Figure 16c). Nevertheless, comparing with scenario 4 (Figure 16d), increasing the installed solar does not contribute to the balance of the system or to consumer satisfaction. Thus, increasing the energy storage system, capable of holding water reserve, is not advantageous to assist the consumption, it being oversized for matching energy sources to periods of high demand (Figure 16c).

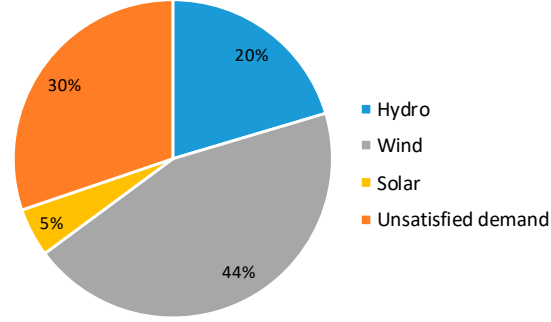

(a)

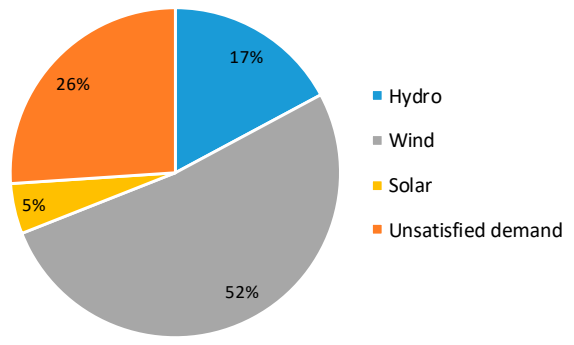

(c)

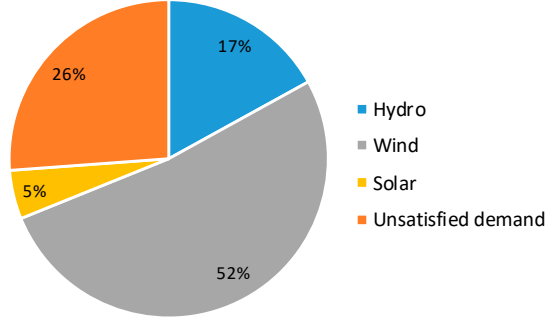

(b)

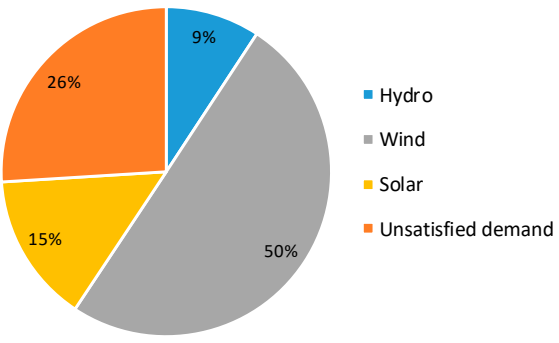

(d)

Figure 16. Satisfied consumption by different energy sources and unsatisfied consumption in (a) scenario 1 ; (b) scenario 2; (c) scenario 3; (d) scenario 4 .

Thus, scenarios 1 and 2 highlight the major concern of renewables. If some of the surplus energy from renewables produced at times of low demand (e.g., solar power in the summer) could be stored and ready for release when demand raises, many of the problems of renewable supply would be solved. However, from the economic point of view, comparing scenario 2 with scenario 1 (Figure 16b), this solution is more expensive, needing estimation costs for the viability of this system.

Thus, a brief economic analysis was conducted, using key financial parameters such as basic payback period $(B P P)$, net present value $(N P V)$ and internal rate of return (IRR) presented in Equations (5)-(7) [40,41].

$$
\begin{gathered}
B P P=\frac{C}{A S} \quad \text { (years) } \\
N P V=\sum \frac{B-C}{(1+r)^{n}} \quad(€) \\
I R R=\sum \frac{B}{(1+r)^{n}}=\sum \frac{C}{(1+r)^{n}}
\end{gathered}
$$

where $B P P$ is the minimum time to recover the total investment (in years), NPV is the presented value of all future income $(€)$, and expenditure flows and IRR is the rate $(\%)$ that makes the NPV zero [41,42]. Regarding $C$, it is the total investment cost; $A S$ is the net annual saving; $B$ is the benefit, $C$ the cost, $r$-the discount rate and $n$-the lifecycle of the project (years). In this study, as suggested by many turbine manufacturers, the lifespan of the project was assumed to be 20 years, and the overall annual interest rate, $r$, is assumed to be $2.5 \%$. The economic analysis results of the hybrid system are presented in Table 5. 
Table 5. Economic analysis results.

\begin{tabular}{ccccc}
\hline Parameters & Scenario 1 & Scenario 2 & Scenario 3 & Scenario 4 \\
\hline Investment Cost $(€)$ & $-3,198,412$ & $-3,781,742$ & $-3,781,742$ & $-4,400,072$ \\
Total annual cost savings and income $(€)$ & 479,762 & 415,992 & 415,992 & 352,006 \\
NPV $(€)$ & $4,611,564$ & $5,452,627$ & $5,452,627$ & $6,344,153$ \\
IRR $(\%)$ & 30.63 & 25.51 & 25.51 & 20.24 \\
BPP (years) & 6.7 & 9.1 & 9.1 & 12.5 \\
\hline
\end{tabular}

Scenario 1 has a relatively basic pay-back period of approximately 7 years with a lower initial capital cost when compared to the other scenarios. Thus, the results yield that scenario 1 is the most economical and reliable solution.

As renewable energy investments represent a significant subset of the infrastructure sector, where $\mathrm{PV}$ and wind power investments have already become well established in the asset allocations of institutional investors, hydropower, by contrast, has a more difficult investment opportunity, since it requires significantly higher up-front investment per capacity unit, making it less scalable than wind power or photovoltaic plants [39-42]. Although, operating pumped-storage power plants is economically viable because electricity can be produced and sold depending on spot market prices, the technical know-how required for hydropower investments is more challenging since the success depends not only on technical and structural components but also on active management.

\section{Water-Energy Nexus}

This research studied a pumped hydro storage serving for on-grid hybrid energy solutions. The complementary characteristics between solar and wind energy output were presented. Results reveal that the wind turbines have a relatively higher share of energy production than PV since the wind energy resource matches better with the load pattern. Peak factors and power capacity were discussed to calculate the overall energy efficiency of the energy storage system. The case study shows that if wind and solar energies are adopted, with power capacities slightly higher than the peak consumption, a better satisfied demand is guaranteed (Figure 17).

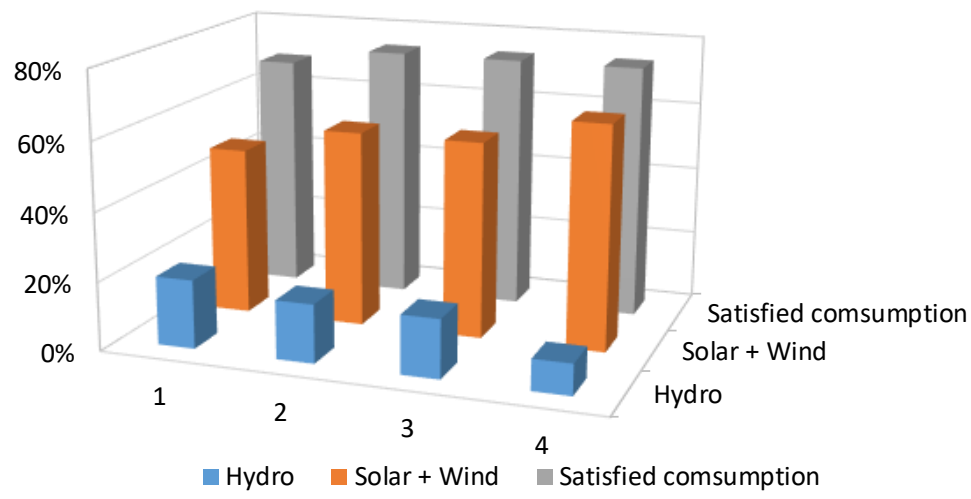

Figure 17. Total satisfied consumption through renewable energy (RE) in each scenario.

In scenarios 2, 3 and 4, the total satisfied consumption is around $74 \%$, against $69 \%$ of scenario 1 , where the wind/solar capacity of 5/0.54 MW becomes attractive to compensate the load (Scenarios 2 and 3).

Moreover, the potential impact of renewables was estimated (Figure 18), illustrating the greenhouse gas emissions avoided as a result of the renewable energies deployment in each scenario in a complementary way, taking as the base stability the pumped-hydro component. Figure $18 \mathrm{~b}$ is the result of the mitigation of climate change effects. 


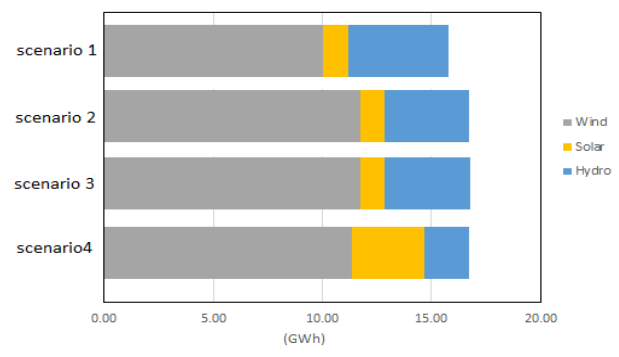

(a)

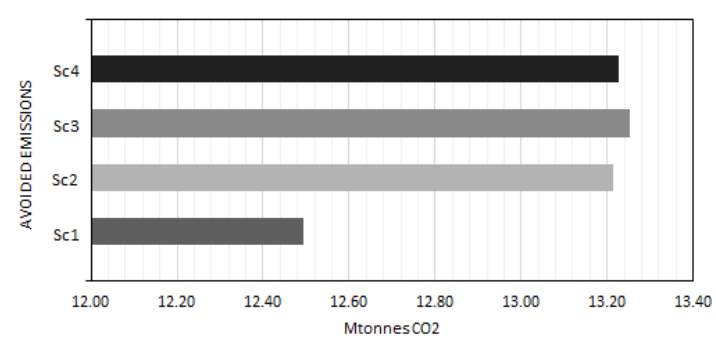

(b)

Figure 18. Electricity generated from renewables (GWh) in each scenario (a); total avoided emissions by each scenario $(\mathbf{b})$.

In scenario 1 , there is a lower $\mathrm{CO}_{2}$ emission and water withdrawal, and a cost-optimal market solution also serves to improve the performance (Table 6). Regarding $\mathrm{CO}_{2}$ and water withdrawal, it remains approximately the same between scenarios 3 and 4 . This shows that storage actions taken in the water infrastructure between these scenarios can serve to improve the electric power infrastructure when the two or more sources are coupled together in a water-energy nexus.

Table 6. Cross comparison of cost, $\mathrm{CO}_{2}$ emissions and water withdrawal in each scenario.

\begin{tabular}{cccc}
\hline Scenario & Cost $\mathbf{( M € )}$ & $\mathbf{C O}_{\mathbf{2}}$ (Mtonnes) & Water Withdrawal $\mathbf{( m}^{\mathbf{3}}$ ) \\
\hline 1 & 3.20 & 2.01 & 169,920 \\
2 & 3.78 & 2.72 & 165,304 \\
3 & 3.78 & 2.76 & 354,304 \\
4 & 4.40 & 2.74 & 357,831 \\
\hline
\end{tabular}

These results suggest an interaction between different renewable sources, which obeys the following pattern: solar energy reduces $\mathrm{CO}_{2}$ emissions but exacerbates the night ramp in energy demand; in contrast, wind energy may bridge this gap, but it is usually intermittent, unpredictable and weather dependent. By employing an energy storage system, the surplus energy can be stored when power generation exceeds demand and then be released to cover the periods when net load exists, providing a robust back-up to intermittent renewable energy. Thus, water and energy storage presents a promising solution to these two problems, as it allows flattening demand curves and significantly reducing costs.

\section{Conclusions}

This work demonstrates that technically the pumped-storage hydropower system integrating other renewable sources is an attractive energy solution. The dynamic contribution of individual sources follows different patterns, due to the stability of hydro by pumping and random variability of other energy sources and the energy demand. Employing the three technologies in a complementary and balanced manner, the hybrid system could generate and store electricity at low cost, facing climate changes and reducing the footprint of electricity in a self-sufficient solution. Thus, a consistent multi-criteria framework was developed to optimize the availability and storage of renewable energy, selecting the best combination of peak factors to achieve the optimum solution in terms of efficiency, energy use, costs and footprint. Important considerations are highlighted and summarized from this multi-variable process:

(a) The optimization showed that in a hybrid solution, turbines and pumps can be used at the same time depending on the intermittency, availability and optimized variables, which include different renewable sources, the storage capacity and the load demand. The pumping system can be supplied by intermittent renewable sources when available, and at the same time, can be guaranteed a constant power production by hydraulic turbines. The only one pipe for the $\mathrm{P} / \mathrm{T}$ 
solution requires different hours for each operation or the use of separate pipes, which can offer more operating flexibility, where one is kept running when the other is stopped or in operation, depending on the sources' availability, constancy or intermittency, type of storage or type of grid connection;

(b) Three sources were combined considering different pump/turbine installations, wind/solar powers and different water batteries as volume capacities. The analysis revealed that $\mathrm{P} / \mathrm{Ts}$ with $4 \mathrm{MW}$ are economically viable compared to $6 \mathrm{MW}$ and $2 \mathrm{MW}$, with $70 \%$ to $85 \%$ satisfaction of consumption levels;

(c) After selecting the best installation power for $\mathrm{P} / \mathrm{Ts}$, four scenarios were tested, changing the wind/solar powers and the water storage capacity. Three types of analyses were performed from the point of view of energy, economy and $\mathrm{CO}_{2}$ emissions. The results obtained show the process of selecting the best scenario is not straightforward, depending on the final goal. Therefore, this analysis unfolds in important points:

i. Scenario 1 stands out from the point of view of reliability and flexibility, where there is a better use of hydropower (Figures 14 and 15), specifically to accommodate the largest shares of other intermittent renewable (solar and wind) energies with a better bridge and compensation between these energy sources;

ii. Scenario 2 showed a $4 \%$ increase in satisfied consumption from an operational point of view, maintaining the same characteristics as scenario 1 but requiring an increase in the installed wind power;

iii. In scenario 3, increasing storage capacity to $288 \mathrm{MWh}$ does not make a significant contribution to the best operation of the system. As a result, the reservoir is oversized to meet the satisfied consumption, i.e., there is a dependency not only on the maximum daily energy use of the system but also on the hydropower system;

iv. In both scenarios 1 and 2, surplus energy from renewables produced at times of low demand (e.g., solar power in summer) can be stored and ready for release when demand rises;

v. Scenario 1 offers more advantages and greater economic viability also in terms of $\mathrm{CO}_{2}$ emissions. This hybrid solution is less expensive, with an interesting pay-back period of 7 years, considering the powers installed, with a lower initial capital cost than that of the other scenarios.

Additionally, it can be concluded that replacing fossil fuels by renewable energies requires (i) distributing installations (e.g., wind turbines) widely; (ii) using a range of different intermittent energy sources, especially those that are partially complementary (e.g., sunny weather often means light winds and vice versa); (iii) matching with suitable management of energy sources in periods of high demand. Still, there is clear evidence of how all these modern integrated techniques for complementarity between renewable sources can significantly reduce electricity tariffs and increase the reliability of the energy supply as main targets of hybrid-energy solutions.

Author Contributions: The author M.S. has been involved in the mathematical modelling, in writing the paper, as well as in the analysis of the results. H.M.R. has contributed with the idea, the revision of the document, the supervision of the whole research, and the analyses of the head drop in each system component. All authors have read and agreed to the published version of the manuscript.

Funding: This research is supported by the project REDAWN (Reducing Energy Dependency in Atlantic Area Water Networks) EAPA_198/2016 from INTERREG ATLANTIC AREA PROGRAMME 2014-2020.

Acknowledgments: The authors wish to thank to the project REDAWN (Reducing Energy Dependency in Atlantic Area Water Networks) EAPA_198/2016 from INTERREG ATLANTIC AREA PROGRAMME 2014-2020 and CERIS (CEHIDRO-IST).

Conflicts of Interest: The authors declare no conflict of interest. 


\section{Nomenclature}

\begin{tabular}{|c|c|}
\hline$A S$ & net annual saving $(€)$ \\
\hline$B$ & benefit $(€)$ \\
\hline$B P P$ & basic payback period (years) \\
\hline$c_{p}$ & coefficient of the pump/motor unit $\left(\mathrm{m}^{3} / \mathrm{kWh}\right)$ \\
\hline$c_{t}$ & turbine generating coefficient $\left(\mathrm{kWh} / \mathrm{m}^{3}\right)$ \\
\hline $\mathrm{C}$ & total investment cost $(€)$ \\
\hline$C_{P / T}$ & pump/turbine energy solution cost $(€)$ \\
\hline$C_{P H S}$ & Pump hydro system cost $(€)$ \\
\hline$C w$ & wind energy solution cost $(€)$ \\
\hline$E_{i}^{p}$ & Pump power installed (MW) \\
\hline$E_{i}^{t}$ & Turbine power installed (MW) \\
\hline$G^{l}$ & acceleration due to gravity $\left(\mathrm{m} / \mathrm{s}^{2}\right)$ \\
\hline$H$ & hybrid power/energy available (MW) \\
\hline$H$ & net head (m) \\
\hline IRR & internal rate of return $(\%)$ \\
\hline$N$ & lifecycle of the project (years) \\
\hline$N P V$ & net present value $(€)$ \\
\hline$p_{f}$ & peak factors \\
\hline Ps & solar power (MW) \\
\hline PHS & pumped hydro storage \\
\hline$P w$ & wind power (MW) \\
\hline$Q^{p}$ & pump flow $\left(\mathrm{m}^{3} / \mathrm{s}\right)$ \\
\hline$Q^{t}$ & turbine flow $\left(\mathrm{m}^{3} / \mathrm{s}\right)$ \\
\hline$R$ & the discount rate $(\%)$ \\
\hline$S$ & solar energy (MW) \\
\hline$V$ & storage capacity $\left(\mathrm{m}^{3}\right)$ \\
\hline$V^{p}$ & pump volume $\left(\mathrm{m}^{3}\right)$ \\
\hline$V^{r e s}$ & volume of the reservoir $\left(\mathrm{m}^{3}\right)$ \\
\hline$V_{\max }^{r e s}$ & maximum volume of the reservoir $\left(\mathrm{m}^{3}\right)$ \\
\hline$V_{\min }^{\text {res }}$ & minimum volume of the reservoir $\left(\mathrm{m}^{3}\right)$ \\
\hline$V^{t}$ & turbine volume $\left(\mathrm{m}^{3}\right)$ \\
\hline$W$ & wind energy (MW) \\
\hline \multicolumn{2}{|c|}{ Greek letters } \\
\hline$\eta_{p}$ & pumping efficiency (\%) \\
\hline$\eta_{t}$ & efficiency of the turbine/generator unit (\%) \\
\hline$\rho$ & density of the water $\left(\mathrm{kg} / \mathrm{m}^{3}\right)$ \\
\hline
\end{tabular}

\section{References}

1. IHA. The World's Water Battery: Pumped Hydropower Storage and the Clean Energy Transition; International Hydropower Association, IHA Working Paper: London, UK, 2018.

2. IHA. Pumped Storage Hydropower Has 'Crucial Role' in Europe's Energy Strategy; International Hydropower Association, IHA Working Paper: London, UK, 2020.

3. Bhandari, B.; Poudel, S.R.; Lee, K.-T.; Ahn, S.-H. Mathematical modeling of hybrid renewable energy system: A review on small hydro-solar-wind power generation. Int. J. Precis. Eng. Manuf. Technol. 2014, 1, 157-173. [CrossRef]

4. Hong, C.-M.; Ou, T.-C.; Lu, K.-H. Development of intelligent MPPT (maximum power point tracking) control for a grid-connected hybrid power generation system. Energy 2013, 50, 270-279. [CrossRef]

5. Kapsali, M.; Kaldellis, J. Combining hydro and variable wind power generation by means of pumped-storage under economically viable terms. Appl. Energy 2010, 87, 3475-3485. [CrossRef]

6. Xu, B.; Chen, D.; Venkateshkumar, M.; Xiao, Y.; Yue, Y.; Xing, Y.; Li, P. Modeling a pumped storage hydropower integrated to a hybrid power system with solar-wind power and its stability analysis. Appl. Energy 2019, 248, 446-462. [CrossRef] 
7. Vieira, F.; Ramos, H.M. Optimization of operational planning for wind/hydro hybrid water supply systems. Renew. Energy 2009, 34, 928-936. [CrossRef]

8. Kocaman, A.S.; Modi, V. Value of pumped hydro storage in a hybrid energy generation and allocation system. Appl. Energy 2017, 205, 1202-1215. [CrossRef]

9. Kapsali, M.; Anagnostopoulos, J.; Kaldellis, J. Wind powered pumped-hydro storage systems for remote islands: A complete sensitivity analysis based on economic perspectives. Appl. Energy 2012, 99, 430-444. [CrossRef]

10. Deason, W. Comparison of $100 \%$ renewable energy system scenarios with a focus on flexibility and cost. Renew. Sustain. Energy Rev. 2018, 82, 3168-3178. [CrossRef]

11. Jaramillo-Duque, Á.; Castronuovo, E.D.; Sánchez, I.; Usaola, J. Optimal operation of a pumped-storage hydro plant that compensates the imbalances of a wind power producer. Electr. Power Syst. Res. 2011, 81, 1767-1777. [CrossRef]

12. Yang, W.; Yang, J. Advantage of variable-speed pumped storage plants for mitigating wind power variations: Integrated modelling and performance assessment. Appl. Energy 2019, 237, 720-732. [CrossRef]

13. Li, J.; Wang, S.; Ye, L.; Fang, J. A coordinated dispatch method with pumped-storage and battery-storage for compensating the variation of wind power. Prot. Control. Mod. Power Syst. 2018, 3, 2. [CrossRef]

14. Nema, P.; Nema, R.; Rangnekar, S. A current and future state of art development of hybrid energy system using wind and PV-solar: A review. Renew. Sustain. Energy Rev. 2009, 13, 2096-2103. [CrossRef]

15. Van Meerwijk, A.J.H.; Benders, R.M.J.; Davila-Martinez, A.; Laugs, G.A.H. Swiss pumped hydro storage potential for Germany's electricity system under high penetration of intermittent renewable energy. J. Mod. Power Syst. Clean Energy 2016, 4, 542-553. [CrossRef]

16. Ramli, M.A.M.; Bouchekara, H.R.E.H.; Alghamdi, A.S. Optimal sizing of PV/wind/diesel hybrid microgrid system using multi-objective self-adaptive differential evolution algorithm. Renew. Energy 2018, 121, 400-411. [CrossRef]

17. Ashok, S. Optimised model for community-based hybrid energy system. Renew. Energy 2007, 32, $1155-1164$. [CrossRef]

18. Sawle, Y.; Gupta, S.; Bohre, A.K. Review of hybrid renewable energy systems with comparative analysis of off-grid hybrid system. Renew. Sustain. Energy Rev. 2018, 81, 2217-2235. [CrossRef]

19. Diaf, S.; Notton, G.; Belhamel, M.; Haddadi, M.; Louche, A. Design and techno-economical optimization for hybrid PV/wind system under various meteorological conditions. Appl. Energy 2008, 85, 968-987. [CrossRef]

20. Kusakana, K. Optimal scheduling for distributed hybrid system with pumped hydro storage. Energy Convers. Manag. 2016, 111, 253-260. [CrossRef]

21. Ma, T.; Yang, H.; Lu, L.; Peng, J. Technical feasibility study on a standalone hybrid solar-wind system with pumped hydro storage for a remote island in Hong Kong. Renew. Energy 2014, 69, 7-15. [CrossRef]

22. Ma, T.; Yang, H.; Lu, L.; Peng, J. Optimal design of an autonomous solar-wind-pumped storage power supply system. Appl. Energy 2015, 160, 728-736. [CrossRef]

23. Bajpai, P.; Dash, V. Hybrid renewable energy systems for power generation in stand-alone applications: A review. Renew. Sustain. Energy Rev. 2012, 16, 2926-2939. [CrossRef]

24. Hana, A.M.H.A.; Zakaria, A.; Jani, J.; Seyajah, N. Optimization Techniques and Multi-Objective Analysis in Hybrid Solar-Wind Power Systems for Grid-Connected Supply. IOP Conf. Ser. Mater. Sci. Eng. 2019, 538, 012040. [CrossRef]

25. Rehman, S.; Al-Hadhrami, L.M.; Alam, M. Pumped hydro energy storage system: A technological review. Renew. Sustain. Energy Rev. 2015, 44, 586-598. [CrossRef]

26. Paska, J.; Biczel, P.; Kłos, M. Hybrid power systems-An effective way of utilising primary energy sources. Renew. Energy 2009, 34, 2414-2421. [CrossRef]

27. Zhang, L.; Xin, H.; Wu, J.; Ju, L.; Tan, Z. A Multiobjective Robust Scheduling Optimization Mode for Multienergy Hybrid System Integrated by Wind Power, Solar Photovoltaic Power, and Pumped Storage Power. Math. Probl. Eng. 2017, 2017, 1-15. [CrossRef]

28. Amaro, G.; Ramos, H.M. Solução Energética Híbrida com Armazenamento por Bombagem: Modelação, Análises de Sensibilidade e caso de Estudo Mestrado Integrado em Engenharia Civil Júri; Instituto Superior Técnico-Universidade de Lisboa: Lisboa, Portugal, 2018.

29. Mohanraj, K.; Bharathnarayanan, S. Three Level SEPIC For Hybrid Wind-Solar Energy Systems. Energy Procedia 2017, 117, 120-127. [CrossRef] 
30. El-Jamal, G.; Ghandour, M.; Ibrahim, H.; Assi, A. Technical feasibility study of solar-pumped hydro storage in Lebanon. Proceedings of 2014 International Conference on Renewable Energies for Developing Countries, Beirut, Lebanon, 26-27 November 2014; Institute of Electrical and Electronics Engineers (IEEE): Beirut, Lebanon, 2014; pp. 23-28.

31. Canales, F.A.; Beluco, A. Modeling pumped hydro storage with the micropower optimization model (HOMER). J. Renew. Sustain. Energy 2014, 6, 43131. [CrossRef]

32. Li, J.; Fang, J.; Wen, I.; Pan, Y.; Ding, Q. Optimal trade-off between regulation and wind curtailment in the economic dispatch problem. CSEE J. Power Energy Syst. 2015, 1, 37-45. [CrossRef]

33. Canales, F.A.; Beluco, A.; Mendes, C.A.B. Modelling a hydropower plant with reservoir with the micropower optimisation model (HOMER). Int. J. Sustain. Energy 2015, 36, 654-667. [CrossRef]

34. Katsaprakakis, D.A.; Christakis, D.G.; Stefanakis, I.; Spanos, P.; Stefanakis, N. Technical details regarding the design, the construction and the operation of seawater pumped storage systems. Energy 2013, 55, 619-630. [CrossRef]

35. Li, S.; Sun, F.; He, H.; Chen, Y. Optimization for a Grid-connected Hybrid PV-wind-retired HEV Battery Microgrid System. Energy Procedia 2017, 105, 1634-1643. [CrossRef]

36. Schmidt, J.; Kemmetmüller, W.; Kugi, A. Modeling and static optimization of a variable speed pumped storage power plant. Renew. Energy 2017, 111, 38-51. [CrossRef]

37. Carravetta, S.A.; Ramos, H.M.; Houreh, S.D. Pumps as Turbines, Fundamentals and Applications; Springer International Publishing: Berlin/Heidelberg, Germany, 2018.

38. Bilal, B.O.; Sambou, V.; Ndiaye, P.; Kébé, C.; Ndongo, M. Optimal design of a hybrid solar-wind-battery system using the minimization of the annualized cost system and the minimization of the loss of power supply probability (LPSP). Renew. Energy 2010, 35, 2388-2390. [CrossRef]

39. Goyena, R. Summary for Policymakers. In Climate Change 2013-The Physical Science Basis; Intergovernmental Panel on Climate Change, Ed.; Cambridge University Press: Cambridge, UK, 2019; Volume 53, pp. 1-30.

40. Luo, W.; Jiang, J.; Liu, H. Frequency-adaptive modified comb-filter-based phase-locked loop for a doubly-fed adjustable-speed pumped-storage hydropower plant under distorted grid conditions. Energies 2017, 10, 737. [CrossRef]

41. Kose, F.; Kaya, M.N.; Ozgoren, M. Use of Pumped Hydro Energy Storage to Complement Wind Energy-A case study. Therm. Sci. 2020, 24,777-785. [CrossRef]

42. Nikolaou, T.; Stavrakakis, G.; Tsamoudalis, K. Modeling and optimal dimensioning of a pumped- 2 hydro energy storage system for the exploitation of 3 the rejected wind energy in the non-Interconnected 4 electrical power system of the Crete island, Greece. Energies 2020, 13, 2705. [CrossRef]

(C) 2020 by the authors. Licensee MDPI, Basel, Switzerland. This article is an open access article distributed under the terms and conditions of the Creative Commons Attribution (CC BY) license (http://creativecommons.org/licenses/by/4.0/). 